\title{
Key mechanisms governing resolution of lung inflammation
}

\author{
C. T. $\operatorname{Robb}^{1}$ - K. H. $\operatorname{Regan}^{1}$ - D. A. Dorward ${ }^{1}$ - A. G. $\operatorname{Rossi}^{1}$
}

Received: 4 February 2016 / Accepted: 14 April 2016/Published online: 27 April 2016

(C) The Author(s) 2016. This article is published with open access at Springerlink.com

\begin{abstract}
Innate immunity normally provides excellent defence against invading microorganisms. Acute inflammation is a form of innate immune defence and represents one of the primary responses to injury, infection and irritation, largely mediated by granulocyte effector cells such as neutrophils and eosinophils. Failure to remove an inflammatory stimulus (often resulting in failed resolution of inflammation) can lead to chronic inflammation resulting in tissue injury caused by high numbers of infiltrating activated granulocytes. Successful resolution of inflammation is dependent upon the removal of these cells. Under normal physiological conditions, apoptosis (programmed cell death) precedes phagocytic recognition and clearance of these cells by, for example, macrophages, dendritic and epithelial cells (a process known as efferocytosis). Inflammation contributes to immune defence within the respiratory mucosa (responsible for gas exchange) because lung epithelia are continuously exposed to a multiplicity of airborne pathogens, allergens and foreign particles. Failure to resolve inflammation within the respiratory mucosa is a major contributor of numerous lung diseases. This review will summarise the major mechanisms regulating lung inflammation, including key cellular interplays such as apoptotic cell clearance by alveolar macrophages and macrophage/neutrophil/epithelial cell interactions. The different acute and chronic inflammatory disease states caused by dysregulated/ impaired resolution of lung inflammation will be discussed.
\end{abstract}

This submission is related to Immunopathology of Lung Diseases - Drs. Tracy Hussel and Aleksander Grabiec

A. G. Rossi

a.g.rossi@ed.ac.uk

1 MRC Centre for Inflammation Research, The Queen's Medical Research Institute, University of Edinburgh Medical School, 47 Little France Crescent, Edinburgh EH16 4TJ, UK
Furthermore, the resolution of lung inflammation during neutrophil/eosinophil-dominant lung injury or enhanced resolution driven via pharmacological manipulation will also be considered.

Keywords Neutrophils $\cdot$ Eosinophils $\cdot$ Macrophages $\cdot$ Lung inflammation $\cdot$ Lung diseases $\cdot$ Pro-resolution mediators ·

Apoptosis $\cdot$ ETosis $\cdot$ Efferocytosis

\section{Introduction}

Acute inflammatory responses are initiated by injury, infection and irritation which, in turn, protect the host from systemic infection and help to restore tissue homeostasis [1]. Inflammation therefore represents a crucial defence mechanism that is protective and vital to health $[2,3]$. Typically, the molecular events and cellular interplays prevalent during acute inflammatory responses are efficient at minimising impending injury, infection or irritation, which leads importantly to restoration of tissue homeostasis and thus complete resolution of the acute inflammatory response. However, if an acute inflammatory response is mounted that is uncontrolled in terms of magnitude or duration, it can lead to disease $[1,3]$. In the lung, dysregulated acute inflammation can result in lung injury contributing to pulmonary fibrosis that severely impairs essential gas exchange processes. Therefore, numerous mechanisms exist, which tightly regulate the gravity and duration of lung inflammation. If unresolved, acute lung injury (ALI) and/ or lung inflammation can progress to chronic inflammation, which occurs in lung diseases such as acute respiratory distress syndrome (ARDS), asthma, cystic fibrosis (CF) and chronic obstructive pulmonary disease (COPD) [1].

Pro-resolution of inflammation was previously regarded as a passive process, with limited understanding of mechanisms 
regulating the resolution of inflammation. However, over the years, substantial research in this field has identified inflammation resolution as an active and highly regulated cellular and biochemical process. It is now known that numerous molecular mediators of inflammation exist, including many proand anti-inflammatory cytokines and chemokines, with attenuation of pro-inflammatory mediator effects assisting in the successful 'switching off' of inflammation [4]. More recently, several endogenous pro-resolving bioactive lipid mediators (immunoresolvents) have been discovered such as lipoxins, resolvins, protectins and maresins, which are heavily involved in driving 'programmed resolution' that successfully terminate inflammation [5-8]. Other key processes governing the successful resolution of inflammation include the phagocytic clearance of apoptotic cells $[9,10]$ during a process referred to as efferocytosis that also results in the phagocytic cells, switching phenotype from a pro-inflammatory cell to a more anti-inflammatory/pro-resolution phenotype $[10,11]$. Also, pertinent to the lung mucociliary clearance of infective agents, allergens, foreign particles and effete cells occur [12]. This review encompasses the cellular mechanisms and chief biochemical mediators involved in the resolution of lung inflammation and repair of damaged tissues, with a specific focus on neutrophil/eosinophil-dominant lung inflammation and pharmacological approaches to drive resolution [13-16].

\section{Cells of the innate immune system}

Antigen-independent innate immunity provides the first line of leukocytic defence against invading microorganisms during which inflammation is an early key response to infection, injury or irritation. Innate immune defence during lung inflammation involves several cell types and cellular interplay. These include leukocytes such as polymorphonuclear granulocytes (neutrophils, eosinophils, basophils) and agranulocytes (monocytes, macrophages), lung epithelial/ endothelial cells, mast cells, natural killer (NK cells) and dendritic cells. These cells can influence the function of other cell types, such as innate lymphoid cells [17] and lymphocytes [18], which are not specifically covered in this current review.

\section{Neutrophils}

Neutrophils, accounting for $70 \%$ of the circulating human blood leukocytes, are short lived in the circulation surviving for up to 7-10 $\mathrm{h}$ (although the precise length of time in the circulation remains controversial; see Tak et al [19]). However, during an inflammatory scenario or in response to chemical stimuli, they can survive up to, or greater than, $48 \mathrm{~h}$. These cells, typically $12-15 \mu \mathrm{m}$ in diameter, contain a distinct multi-lobed nucleus and possess four different types of granules, primary (azurophilic), secondary (specific), gelatinase and secretory. These granules contain $>300$ proteins which are involved in several cell processes including migration, adhesion and anti-microbial activity [20]. Neutrophils are very versatile and upon inflammatory insult, rapidly migrate to the foci of injury/infection, where they are often first on the scene and help defend the host via phagocytosis, degranulation, generation of reactive oxygen species (ROS) or by releasing webs of chromatin via neutrophil extracellular traps (NETs) generation to trap and kill microorganisms. Furthermore, there is evidence that neutrophils can change from a pro-inflammatory to an anti-inflammatory phenotype following a successful inflammatory response. In such an instance, neutrophils stop producing and releasing pro-inflammatory mediators such as leukotriene $\mathrm{B}_{4}\left(\mathrm{LTB}_{4}\right)$ and platelet-activating factor $(\mathrm{PAF})$ and start to produce and release pro-resolving mediators such as pro-resolving bioactive lipids (e.g. lipoxins) which enhance the resolution phase of inflammation [21], for a thorough review of the pro-resolution properties exhibited by neutrophils [see 22]. Once the neutrophil has fulfilled its physiological function, they normally undergo apoptosis which retains membrane integrity, thus preventing uncontrolled release of noxious cellular contents and internalised microbes to the immediate extracellular environment [23]. Apoptosis-specific cell changes promote the recognition and uptake of neutrophils by phagocytes such as macrophages, dendritic cells and epithelial cells. It is essential for the successful resolution of inflammation that neutrophils are 'switched off', undergo apoptosis and are successfully cleared. If unresolved, acute inflammation can lead to chronic inflammation where mass neutrophil influx to a localised vicinity results in host tissue damage. This can occur when excess neutrophils produce free radical species during ROS generation, release proteolytic and anti-microbial granule contents during de-granulation and externalisation chromatin studded with nuclear, granular and cytosolic proteins with high anti-microbial properties during NET generation. Moreover, during hypoxic conditions ( $1 \%$ oxygen) which are commonly experienced throughout inflammation, hypoxia-induced neutrophil survival is observed, mediated by hypoxia-inducible factor (HIF)- $1 \alpha$-dependent nuclear factor kappa light chain enhancer of activated B cells (NF- B) activity and prolyl hydroxylase 3 expression. Like lymphocytes and macrophages, evidence suggests that neutrophils can also exist as a heterogeneous population exhibiting different phenotypes [24, 25]. Interestingly, accumulating recent evidence indicates that neutrophils, depending of the inflammatory response, may be capable of leaving the vicinity of inflammatory site by a process termed reverse migration [26-32]. Neutrophil-dominant inflammation is implicated in a number of inflammatory lung diseases including ALI/ARDS, CF, COPD, idiopathic pulmonary fibrosis (IPF), bronchiectasis, atopic/non-atopic asthma and severe asthma, during which neutrophil numbers are elevated (neutrophilic asthma). 


\section{Eosinophils}

These cells make up $<5 \%$ of the circulating human blood leukocytes and can survive for up to $12 \mathrm{~h}$ but if necessary have the ability to prolong their life span for at least a week. They are slightly larger than neutrophils with a diameter of $12-$ $17 \mu \mathrm{m}$, possess a bi-lobed nucleus and are easily identifiable via Romanowsky staining (methylene blue and eosin). Like neutrophils, eosinophils are loaded with granules in their cytoplasm; however, eosinophilic granules contain different components such as eosinophilic cationic protein, major basic protein, eosinophil peroxidase and eosinophil-derived neurotoxin, which are cytotoxic to airway epithelial cells. On arrival to the site of injury/infection (especially parasitic infection), eosinophils undergo degranulation which aids in removal of the inflammatory stimuli circumventing further inflammation. Eosinophils can also contribute to host defence via release of eosinophil extracellular traps (EETs) composed of either mitochondrial or nuclear DNA [33, 34]. These EETs contribute to anti-microbial defence via release of mitochondrial DNA that associates with eosinophil-derived granule proteins capable of capturing and killing microorganisms in vitro and in vivo [33]. Eosinophils can also undergo apoptosis, which are then cleared via phagocytosis by macrophages, modulated by IL-5 [35]. Eosinophils are capable of displaying both proinflammatory and anti-inflammatory phenotype and function. Anti-inflammatory activities of eosinophils include an important regulatory role during hypersensitivity reactions via eosinophil peroxidase-mediated inactivation of $\mathrm{LTB}_{4}, \mathrm{C}_{4}$ and $\mathrm{D}_{4}$ [36]. However, eosinophil peroxidase can also exert proinflammatory activities in areas of inflammation where mast cells and eosinophils are both present, largely via extracellular formation of active complexes formed between eosinophil peroxidase and mast cell granules [37]. Anti-viral activity has also been documented for human eosinophils and their associated ribonucleases against respiratory syncytial virus (in vitro) and for mice eosinophils and associated ribonucleases against pneumonia virus of mice in vivo (for review, see Rosenberg and Domachowske [38]). Furthermore, human and mouse eosinophils are capable of displaying anti-viral activity against parainfluenza 1 in the lung (a common respiratory virus) [39]. Eosinophils are dominant during allergic airway inflammation [40], including atopic/non-atopic asthma and allergic rhinitis, and are known to be involved in the maintenance and restoration of lung homeostasis.

\section{Basophils}

Basophils represent the rarest of the circulating human granulocytes, and their granules contain a variety of substances including histamine, heparin, serotonin, neutral proteases and hydrolases. Upon stimulation, they are capable of releasing their granule contents and synthesis of mediators including bioactive lipids and cytokines. Thus, upon exposure to allergens, they become activated and rapidly degranulate, which exaggerates inflammation during atopic/non-atopic asthma and allergic rhinitis [41].

\section{Monocytes/macrophages}

Monocytes contain numerous granules smaller than those of their granulocyte counterparts, which mostly contain lysosomal enzymes which aid in the destruction of internalised phagocytosed microorganisms. In the absence of inflammation, monocytes are normally confined to the bone marrow and blood. However, upon inflammatory insult, they rapidly migrate to inflamed tissue and differentiate into large tissue resident phagocytic macrophages. Depending on the microenvironment, macrophages can change their status to a variety of phenotypes. Please note that for convenience, macrophages have been classified into different phenotypes; this nomenclature is not precise and the authors note that the macrophage is plastic and can change depending on environment, origin and activation status. For example, they can have a more proinflammatory phenotype (often termed as M1 or classical macrophages), anti-inflammatory phenotype (termed M2 or alternative macrophages) or pro-resolving phenotype [11, 42, 43]. M1 switching can be induced by intracellular pathogens, bacterial cell wall components such as lipopolysaccharide (LPS), lipoproteins and soluble mediators such as the cytokines interferon gamma (IFN $\gamma$ ) and tumour necrosis factor (TNF), which, in turn, lead to release of various proinflammatory cytokines/mediators (IL-1, IL-6, IL-8, TNF, IFN $\gamma, \mathrm{LTB}_{4}$ ) exacerbating inflammation, as well as nitric oxide (NO) generation which aids in efficient killing of microorganisms [44]. M2 switching can be induced by various parasites and fungal cells; immune complexes; apoptotic cells; and soluble mediators including macrophage colonystimulating factor (M-CSF), IL-4, IL-10, IL-13 and transforming growth factor beta (TGF $\beta)$ [45]. M2 macrophages shut down the release of pro-inflammatory stimuli and release pro-repair and anti-inflammatory cytokines/ mediators such as IL-10, TGF $\beta$ and prostaglandin $\mathrm{E}_{2}$ $\left(\mathrm{PGE}_{2}\right)$. Furthermore, M2 macrophages have enhanced phagocytic capabilities, with their most important function being the efficient clearance of apoptotic cells [46], which contributes largely to the successful resolution of inflammation. During lung infection and injury, migration and retention of monocyte and macrophage populations are implicated in triggering and sustaining pulmonary inflammation [47].

\section{Lung epithelial/endothelial cells}

In the airways, the trachea, combined with main bronchi, constitute proximal cartilaginous airways and are responsible for the conduction of inhaled air. During breathing, the proximal 
pseudostratified epithelium participates in defence against environmental toxins and invading microorganisms. Conversely, a more columnar epithelium is located in distal airways, where high numbers of goblet and ciliated epithelial cells are situated. Goblet epithelial cells secret mucous, which provides lubrication to assist ciliated epithelial cells in sweeping microorganisms, dust particles and effete cells away from the lungs (mucociliary clearance). The microvascular pulmonary endothelium and epithelial lining of the alveoli form the foundation of the gas exchanging air-blood barriers in the lung. This barrier is composed of three distinct compartments, blood, interstitium and the alveolar space [48]. The alveolar epithelium is made up of type- 1 and type- 2 alveolar cells (pneumocytes), with gas exchange performed by type-1 cells and excretion of pulmonary surfactant performed by type- 2 cells, which maintains normal lung function by reducing surface tension. Alveolar macrophages are also the most abundant phagocytes present in alveolar space within the lung. Owing to their large surface area and the constant onslaught from microorganisms and particulates present in the air, lungs have acquired effective mechanisms for the detection of microbes. In infants, developmental disorders in the extensive interface where alveolar endothelial cells are directly opposite alveolar epithelial cells can lead to severe respiratory complications. In mature lungs, irreparable changes to the structure of the blood-gas interface contribute to fibrotic lung diseases and pulmonary emphysema, whereas dysfunction in the lung endothelial/epithelial cell barrier is a major contributor of ALI. Moreover, in ALI/ARDS, extensive damage to the endothelial/epithelial cell barriers causes leakage of edema fluid and inflammatory cells into the alveolar spaces resulting in hypoxemia and respiratory failure. In terms of reparative capabilities, endothelial cells can facilitate epithelial repair in the lung microenvironment [49].

\section{Mast cells, NK cells and dendritic cells}

Mast cells are thought to be involved in wound healing and repair and are found in skin and mucosal/connective tissues, where upon response to a pathogenic insult preferentially concentrate within mucosal/connective tissues to provide innate immune defence. Mast cells (via degranulation) can release potent inflammatory mediators including histamines, proteases, chemotactic factors, cytokines and arachidonic acid metabolites that impact upon the vasculature, smooth muscle, connective tissue, mucous glands and other inflammatory cells [50]. Like eosinophils and basophils, mast cells are implicated in allergic airway inflammation, with mast cell numbers elevated in pulmonary alveoli and airways, as well as in asthmatic lungs or in bronchial alveolar lavage (BAL) fluid from patients with IPF and sarcoidosis [51]. Other cell types involved in lung inflammation include NK cells and dendritic cells. NK cells are cytotoxic lymphocytes and can play both advantageous and disadvantageous roles during asthma, COPD, influenza and tuberculosis. However, there remains a paucity of knowledge as to how the functions of these cells are regulated in the unique tissue environment of each condition [52]. Dendritic cells are the messengers between the innate and adaptive immune systems. In the lung, dendritic cells create a cellular interphase between the external environment and the microenvironment. Lung dendritic cells play significant roles during the pathogenesis of asthma via regulation of bronchial hyperreactivity, recruitment of eosinophils/mast cells to localities of airway inflammation and induction of hyperplasia in goblet cells [53].

\section{Cell death}

Cell death processes are tightly regulated to safeguard successful resolution of inflammation. Nevertheless, dysregulation of cell death commonly occurs hampering the proresolution process. In the lung, numerous cell death processes govern inflammation. Understanding the mechanisms that regulate cell death in the lung will help enable identification of novel therapeutic targets to limit/resolve inflammation and restore homeostasis.

\section{Apoptosis}

Granulocyte apoptosis has been a subject of much interest over recent decades, and there is strong evidence that failure of inflammation resolution contributes to numerous chronic inflammatory conditions and with its manipulation, therefore offering potential novel therapeutic targets. Inflammatory cells have the potential to be incendiary in the host tissue environment and, in the absence of an appropriate inflammatory 'threat', can trigger host tissue damage secondary to release of histotoxic mediators such as proteases and reactive oxygen species. Perhaps one of the most critical mechanisms for resolution and restoration of tissue homeostasis following an acute inflammatory insult is the ability of accumulated migratory granulocytes to undergo immunologically silent programmed cell death, namely, apoptosis. This highly regulated, energy-dependent and complex process involves the coordinated destruction and packaging of inflammatory cell contents for phagocytic clearance in a manner that does not elicit a host immune response, facilitates healing, and promotes and maintains self-tolerance by the adaptive immune system to create immunological memory. In addition, this neat packaging of cell contents prevents the leakage of proinflammatory mediators and contains histotoxic weaponry, including proteases, reactive oxygen species production and lysozymes. Granulocyte apoptosis is a caspase-dependent process that proceeds following activation of one of two major pathways, the intrinsic and extrinsic [1, 54]. It has become increasingly evident that the mutual exclusivity of these 
pathways is not as clear-cut as was previously assumed, and there is a degree of cross talk between the molecular component of their execution, with both ultimately dependent on the actions of caspases to initiate cell suicide. Caspases, a family of cysteine-aspartic proteases, are the critical intracellular mediators of apoptosis and are also implicated in inflammation and necrosis, thus offering a promising target for pharmacological manipulation $[55,56]$.

The intrinsic, or mitochondrial, pathway occurs when the balance of pro- and anti-apoptotic mediators of the Bcl-2 family proteins tips in favour of cell death, which occurs in response to DNA damage or endoplasmic reticulum stress. In the mature granulocyte, the pro-apoptotic family members, $\mathrm{Bax}, \mathrm{Bad}, \mathrm{Bak}$ and Bid, are suppressed by their antiapoptotic counterparts, Mcl-1, Bcl-xl and A1, thus maintaining cell viability. In the presence of sufficient cellular stress, they circumvent this suppression and translocate from cytoplasm to mitochondria, triggering development of mitochondrial outer membrane permeabilisation (MOMP). MOMP allows mitochondrial molecules cytochrome C, Smac/ DIABLO, Omi/HtrA2 and serine proteases to enter the cytosol, where cytochrome C interacts with Apaf- 1 to form the apoptosome, which is ultimately responsible for cell death via the activation of pro-caspase 9. The resultant caspase 9 causes cleavage of the 'executioner' - caspase 3, leading to DNA fragmentation, cross-linking and degradation of intracellular proteins and membrane receptor switch. Conversely, apoptosis advancing via the extrinsic 'death receptor' pathway occurs in response to stimulation by extracellular mediators, primarily TNF, Fas ligand and tumour necrosis factor-alpharelated apoptosis-inducing ligand (TRAIL) [57]. These intercellular messengers activate receptors on granulocyte plasma membranes - specifically TRAIL receptor (TRAIL-R), TNF receptor 1 (TNFR1) and Fas receptor (FasR), which upon binding with their corresponding ligand are prompted to coalesce. Assemblages of membrane proteins bind with internal adaptors, forming death domain proteins that attract clusters of cytosolic pro-caspase 8 . The interactions of these proteins trigger an intracellular cascade, namely, the death-inducing signalling complex (DISC) that culminates in autocatalytic cleavage of pro-caspase 8 , which then results in apoptosis of the cell again via cleavage of caspase 3 . Caspase 8 generated in response to extracellular Fas ligand is the main executor of cross talk between the intrinsic and extrinsic pathways, as its release triggers MOMP via cleavage of Bid [58, 59].

Following caspase activation, nuclear DNA forms nucleosomes, dense packages of genetic material. Occurring simultaneously is the alteration of the plasma membrane receptor profile. The pro-survival molecule suite, which includes CD47 and CD31, is replaced by a milieu of 'find-me' and 'eat-me' signals that trigger recognition and stimulate uptake of the dying cell by macrophages or other cells with phagocytic capacity $[10,60]$. Find-me signals are released from apoptotic cells which subsequently attract nearby phagocytes. In mammals, several find-me signals have been identified including fractalkine (CX3CL1), lysophosphatidycholine (lipid mediator), sphingosine 1-phosphate and nucleotides including adenosine triphosphate and uridine $5^{\prime}$ triphosphate [61-64]. Eat-me signals allow the specific recognition of apoptotic cells via cell different cell surface changes which include exposure of phosphatidylserine (PS) to the outer membrane leaflet, intracellular adhesion moelecule-1 (ICAM1) epitope alteration, exposure of calreticulin and alteration of cell surface charge and glycosylation configurations (for review, see Gardai et al. [65]). The best described and most evolutionarily conserved of these eat-me signals is the externalisation of PS to the outer membrane leaflet $[66,67]$, which along with ICAM3 and annexin 1 promotes phagocytosis. Additionally, find-me signals such as nucleotides, fractalkine and lipid mediators attract not only professional phagocytes but can also facilitate uptake by neighbouring cells and other non-professional phagocytes including bronchial epithelial cells [10, 68, 69]. In addition to preventing direct, though inadvertent, damage to host tissues, this mechanism of removal dampens the immune response and encourages resolution, allowing normal tissue homeostasis to resume. Apoptosis is an important clearance mechanism for effete cells and for the successful resolution of lung inflammation. Granulocyte apoptosis has been shown to be delayed in lung disease, and specific induction of granulocyte apoptosis can enhance the resolution of lung inflammation (for indepth reviews, please refer to $[1,14])$.

\section{Other cell death processes in the lung}

In direct opposition to its well-tempered counterpart (apoptosis), necrosis results in loss of membrane integrity and the unrestrained release of intracellular contents following cell trauma. The release of toxic damage-associated molecular patterns (DAMPs) into the extracellular environment characteristically results in an acute inflammatory response with inflammatory cell influx, paracrine effects on surrounding cells with release of pro-inflammatory mediators and significant potential for host tissue destruction [70, 71]. A variety of insults, including infection, chemicals, physical trauma and nutritional deficits, cause direct loss of membrane integrity-socalled primary necrosis. In situations where there is a failure in the timely and sufficient clearance of apoptotic cells by phagocytes, secondary necrosis occurs due to the inevitable disintegration of the apoptotic cell membrane, which may result in a late-phase inflammatory response, the nature of which is still debated $[10,60,68]$. There is increasing recognition of the importance of DAMPs in the propagation of the acute inflammatory response within the lung through interaction with pathogen recognition receptors (PRRs) [72]. Their activation promotes inflammation via transcription of pro-inflammatory cytokines and enhances the anti-microbial response. There is 
growing evidence to suggest that secondary necrosis, the necrotic fate of a cell following a failure of phagocytosis once apoptosis has occurred, contributes to persistent inflammation in a number of chronic conditions, and certainly evident that necrosis in the context of hyperactive acute response can result in significant long-term sequelae as a result of tissue damage and aberrant remodelling.

In 2004, a novel cell death process distinctly separate to necrosis and apoptosis was discovered when it was observed that human neutrophils could generate NETs [73] for innate immune defence. NETs are composed of decondensed nuclear chromatin that is discharged to the extracellular environment in a controlled manner. Additionally, neutrophils can release mitochondrial DNA [74]; however, mitochondrial DNA is 100, 000 times less abundant on NETs than nuclear DNA [75]. NETs are characterised by the nuclear membrane being entirely fragmented with most of the granules being dissolved, thus allowing direct contact and mixing of nuclear, cytoplasmic and granular components [76]. Studded on the DNA backbone of NETs are nuclear, granule and cytosolic proteins. Nuclear proteins include citrullinated histones and anti-microbial peptides (AMPs) such as the cathelicidin, LL37; azurophilic (primary) granule proteins such as neutrophil elastase (NE), cathespin G, myeloperoxidase (MPO) and $\alpha$-defensins; specific proteins from secondary and tertiary granules such as lactoferrin and gelatinase, respectively; or cytosolic proteins such as the cytosolic protein complex, calprotectin [73, 77]. The core histones H2A, H2B, H3 and H4 account for $70 \%$ of all NET-associated proteins [77]. Histone hypercitrullination which mediates chromatin decondensation during NET formation is mediated via peptidylarginine deiminase 4 (PAD4) [78].

The formation of NETs is dependent upon generation of ROS via activation of nicotinamide adenine dinucleotide phosphate (NADPH) oxidase, actin filament polymerisation, as well as requiring activation of protein kinase $\mathrm{C}(\mathrm{PKC})$ pathways upstream of NADPH oxidase [76, 79, 80]. NETs have the ability to capture and kill both Gram-positive/negative bacteria, viruses, fungi and larger parasites [73, 81-83]; however, it is now widely regarded that NETs are more efficient at trapping microorganisms as opposed to killing. Having said that, bacteria do have the ability to escape and degrade NETs via numerous mechanisms, for example, polysaccharide formation which causes electrochemical repulsion of AMPs or DNAse generation aiding degradation of chromatin [84, 85]. This process was first termed NETosis [86] as it was thought to be exclusive to neutrophils. However, this cell death pathway is now commonly referred to as ETosis [87] and can be found in a number of different immune cell types, as well as in haemocytes of lower invertebrates [88]. The early origin of ETosis helps explain some of its pathological effects in mammals where ETosis can be viewed as a double-edged sword.

ETosis is implicated in a number of chronic lung inflammatory disorders, including ALI and ARDS, influenza pneumonia, cystic fibrosis, asthma, COPD and tuberculosis. A hallmark of infection-related ALI/ARDS and in sterile injury is the activation and subsequent mass migration of neutrophils into the alveolar space, which is initiated by chemokines released from macrophages, neutrophils and epithelial cells [89]. Neutrophil activation and NET formation in the alveolar space are initiated by a highly localised concentration of stimulating factors. Injury to alveolar epithelial cells increases permeability of the barrier between the alveolar space and blood vessels, which also promotes the epithelium to release pro-inflammatory IL-8. This can result in leakage of edema fluid containing high infiltrating numbers of neutrophils into the alveolar space. Within the alveoli, NETs are released in response to host-derived factors such as granulocyte/macrophage colony-stimulating factor (GM$\mathrm{CSF})$, complement factor $5 \mathrm{a}$ (C5a), activated platelets and singlet oxygen. NETs then cause secondary epithelial cell damage via release of NET proteins and ROS generation, which results in chronic inflammation. Potent lung injury factors released by NETs include NE, which cleaves endothelial cytoskeleton, as well as E-cadherin and VE-cadherin that increase the permeability of the alveolar-capillary barrier [90]. Other NET-derived components such as cathespin G can degrade anti-inflammatory proteins via pro-inflammatory protein production, LL-37 promotes apoptosis in epithelial and endothelial cells and ROS produced by MPO causes both apoptosis and necrosis in epithelial cells [90]. Moreover, extracellular histones ( $\mathrm{H} 3$ and $\mathrm{H} 4)$ released from NETs are implicated as pivotal effectors of C5aR- and C5L2-mediated (C5a receptors) ALI in humans, rats and mice [91]. NETs are also found in models of sterile injury such as transfusion-related ALI (TRALI) [92]. NETs have been linked to ALI in influenza pneumonitis where NETs caused lung injury via association with alveoli in areas of tissue injury [93]. NETs are found in the sputum of CF patients [94]. The majority of extracellular DNA found in the sputum of CF patients is in fact NET derived, as the DNA complexes are consistent with neutrophil ETosis and share a similar protein signature [95]. Extracellular DNA leads to an increase in sputum viscosity that correlates with a high concentration of neutrophils and NET accumulation in CF airways that consequently aids microbial colonisation, proliferation and biofilm formation causing chronic inflammation correlating with increased pulmonary obstruction [96, 97]. Yet, why more ETosis is occurring in CF airways remains unclear. However, it is likely that NETs are formed in response to host bacteria, such as opportunistic Pseudomonas aeruginosa, one of the main pathogens to colonise the CF lung which is also a common pathogen known to induce NETs [97]. Both EETs and NETs are found in the airways of human atopic asthma patients in vivo [98], whereas NETs decorated with NE, histone $\mathrm{H} 1$ and citrullinated histone $\mathrm{H} 3$ are found in sputum of COPD patients [99, 100]. Interestingly, both Mycobacterium 
genotypes $M$. tuberculosis (cause of most types of tuberculosis) and $M$. canetti induced NET formation and ROS production in a time-dependent manner [101]. M. tuberculosis-induced NETs were decorated with key ETotic markers such as histone $\mathrm{H} 2 \mathrm{~A}, \mathrm{H} 2 \mathrm{~B}$ and NE and were able to trap but not kill M. tuberculosis [101]. Granulomas are an important and hallmark feature of tuberculosis and are generally caused by mycobacterial or fungal infections. These prominent structures represent a key immune response to foreign material that is too large to be cleared by other immune defence processes. For an in-depth review of the role of ETosis during lung inflammation, refer to Cheng and Palaniyar [102]. Interestingly, there appears to be a link between NADPH oxidase activation, ETosis and apoptosis in immune defence against infectious agents. This has been highlighted by studies involving neutrophils obtained from patients with chronic granulomatous disease (CGD; a rare inherited disorder of NADPH oxidase) and mouse models of CGD, where in both instances, the ETotic response is severely diminished [76, 103]. Furthermore, following phagocytosis (in vitro), neutrophil apoptosis is compromised in CGD sufferers [104]. Failed resolution of inflammation in patients with CGD can lead to a number of inflammatory lung conditions including pneumonia, pulmonary fibrosis and lung abscesses, and specifically, in CGD mice, ALI can result as a consequence of impaired tryptophan catabolism (a superoxidedependent process) [105].

Additional cell death processes play important roles during lung inflammation; these include autophagy and necroptosis. Autophagy entails the intracellular degradation of cellular components, which are then delivered to the lysosome for enzymatic degradation. Autophagy can play opposing roles during chronic lung inflammatory disorders and lung cancer. An increase in autophagy markers, such as autophagosome formation, and levels of LC3B-II (autophagosomeassociated protein) are found in the pulmonary epithelium after induction of ALI in mice after extended exposure to hyperoxia [106]. During tuberculosis, autophagy can assist in the generation of anti-virulence factors [107], whereas during influenza A, infection autophagy is induced with viral replication dependent upon autophagosome formation [108]. Mitophagy (selective degradation of mitochondria via autophagy) can, in certain instances, aggravate the severity of COPD by activating additional cell death processes, whereas during pulmonary hypertension, autophagy can regulate cell death facilitating host defence [106]. Furthermore, autophagic degradation and clearance of cilia (ciliophagy) result in COPDassociated cilium dysfunction [109]. Impairment of autophagy can escalate the severity of cystic fibrosis and idiopathic pulmonary fibrosis, and in lung cancer, it can reduce carcinogenesis; yet it can also promote tumour cell survival. Therefore, autophagy can control the effectiveness of certain cancer therapies [106]. Conversely, necroptosis (programmed necrosis) is known to augment lung inflammation in several murine models. In a model of erythrocyte transfusion and LPSinduced lung inflammation, necroptosis of lung endothelial cells is induced via high mobility group box 1 (HMGB1) protein [110]. Staphylococcus aureus toxins can induce necroptosis via receptor-interacting protein kinases (RIP) 1 and 2 which bind to pro-necrotic mixed lineage kinase domain-like (MLKL) protein via RIP1/RIP2/MLKL signalling, which results in depletion of alveolar macrophages as well as IL-1 $\beta$ expression leading to pulmonary damage [111]. Necroptosis was also observed in bronchial epithelial cells in vitro via induction by cigarette smoke, which also triggered the release of DAMPs and pro-inflammatory cytokines (IL-8, IL-6) [112]. In vivo, cigarette smoke caused neutrophilic airway inflammation as evidenced by increased the number of neutrophils present in the BAL fluid, which was significantly reduced by treatment with the necroptosis inhibitor, necrostatin-1 [112].

\section{Efferocytosis}

A critical process in the successful resolution on inflammation is the efficient clearance of apoptotic cells by phagocytes during a process termed efferocytosis. This process helps to limit inflammation and maintain tissue homeostasis. Efferocytosis ensures the swift removal of apoptotic cells before they lose membrane integrity and release their histotoxic intracellular contents to surrounding tissues, which would cause host tissue damage and exacerbate inflammation. Apoptotic cells once engulfed are contained within a large fluid-filed vesicle termed an efferosome that fuses with lysosomes to form the efferolysosome, which eventually digests the redundant cell. Efferocytosis is typically performed by professional phagocytes such as macrophages or dendritic cells; however, this process can also be performed by non-professional phagocytes such as epithelial cells and fibroblasts. Before phagocytosis, apoptotic cells undergo characteristic morphological changes such as cell shrinkage, membrane blebbing and karyorrhexis, which enable the dying cell to be recognised, engulfed and subsequently cleared. In most cases, phagocytes engulf dying cells in their entirety, such is the case for macrophages for the clearance of apoptotic neutrophils [113]. However, in certain instances, such as when the target is too large to be efficiently phagocytosed, multiple phagocytes can work in concert by engulfing apoptotic cells in 'bite-sized' portions. Such a scenario is observed during efferocytosis performed by fibroblasts in the absence of macrophages [114] .

\section{Mechanisms}

Recently reviewed by Poon et al., some of the key mechanisms of the efferocytosis process include the release of various find-me and 'keep-out' signals, as well as the presentation 
of various eat-me and 'do not eat-me' signals by apoptotic cells [10]. During early apoptosis, dying cells attract phagocytes via the release of chemotactic factors. These find-me signals can either be soluble or signal through submicron membrane vesicles. Soluble factors include nucleotides that are released from apoptotic cells through caspase-activated pannexin 1 (PANX1) membrane channels [10]. Signalling through submicron membrane vesicles includes microparticle-associated molecules such as $\mathrm{CX} 3$ chemokine ligand 1 ( $\left.\mathrm{CX}_{3} \mathrm{CL} 1\right)$, ICAM3 and the $\mathrm{Ca}^{2+}$-dependent phospholipid-binding protein annexin A1 [10]. Annexin A1 is released when membrane integrity is lost during late apoptosis (secondary necrosis) and is known to promote recruitment of monocytes via proteolytic processing of a dis-integrin and metalloproteinase domain-containing protein 10 (ADAM10) [115] as well as promoting apoptotic cell engulfment and clearance $[115,116]$. Interestingly, apoptotic cells also possess the ability to deter recruitment of proinflammatory cells via release of keep-out signals, which function as negative regulators of granulocyte migration. At present, the glycoprotein lactoferrin is the only known keepout signal and is released from various apoptotic cell types, which subsequently inhibits neutrophil migration in vitro and in vivo [117] and eosinophil migration in vitro [118]. Various cell surface eat-me signals help phagocytes distinguish viable cells from apoptotic cells. The main eat-me signal exposed on the surface of apoptotic cells is the membrane phospholipid PS [66]. In viable cells, PS is confined to the inner membrane via the transmembrane lipid transporter protein flippase. However, during early-stage apoptosis, PS is translocated from the inner to the outer membrane leaflet via the activity of phospholipid scramblase. PS exposed on the surface of apoptotic cells can be detected by phagocytes via several recognition mechanisms. Direct detection of PS occurs via different membrane receptors, including brain-specific angiogenesis inhibitor 1 (BAI1) [119], stabilin-2 [120] and protein family members of the $\mathrm{T}$ cell immunoglobulin domain (TIM), specifically TIM1, TIM3 and TIM4 [121, 122]. Recognition of PS via BAI1 results in rearrangement of the cytoskeleton to aid phagocytic engulfment, which is mediated via the engulfment and cell motility protein 1 (ELMO1)-dedicator of cytokinesis-180 (DOCK180)-Ras-related C3 botulinum toxin substrate (RAC) (ELMO1-DOCK180-RAC) complex [119]. Stabilin-2 initiates apoptotic cell uptake via PS binding mediated by interactions with the engulfment adapter protein (GULP) and thymosin $\beta 4$ (regulates actin polymerisation) $[123,124]$, whereas TIM4 predominantly functions as a tethering protein for PS where phagocytic engulfment is facilitated via signalling of associated proteins [125]. Aside from these genuine PS membrane receptors, PS can also be bound by bridging molecules including milk fat globule-endothelial growth factor 8 (MFG-E8), protein S and Gas6 which are ligands recognised by their cell surface receptors on phagocytes, specifically the $\alpha_{v} \beta_{3}$ integrin family of receptors in the case of MFG-E8 and the Tyro3-Axl-Mer (TAM) family of receptors in the case of protein S and Gas6 [126-128]. Apoptotic cells can also expose calreticulin (endoplasmic reticulum resident protein 60 ) on their surface, which can serve as an additional eat-me signal. For example, translocation of calreticulin from the endoplasmic reticulum to the plasma membrane occurs during induction of apoptosis accompanied by endoplasmic reticulum stress in cancer cells, which are in turn subsequently cleared by phagocytes via CD91 (low-density lipoprotein-receptor protein) detection of calreticulin $[129,130]$. In contrast to eat-me signals, cells can also expose do not eat-me signals on their cell surface. This is the case for viable cells that can, under certain physiological circumstances, translocate PS to their outer membrane leaflet. However, these viable cells avoid phagocytic uptake by exposure of do not eat-me signals such as CD31, CD47 and CD46 [10].

\section{Regulation}

Phagocytic functions can be augmented by exposure or treatment with glucocorticoids (GCs). GCs can also stimulate macrophages to switch to an anti-inflammatory phenotype (M2) where they shut down release of pro-inflammatory cytokines and simultaneously release anti-inflammatory cytokines (IL10 , TGF $\beta$, IL-1ra), helping to promote resolution of inflammation and tissue repair. GCs are a class of corticosteroids which are a class of steroid hormones regularly used for the treatment of inflammatory diseases due to their potent antiinflammatory properties. Cortisol is an important endogenous GC heavily involved in modulation of various metabolic, homeostatic, immunologic and cardiovascular functions. However, under certain chronic inflammatory conditions, endogenous levels of cortisol are not enough to suppress such inflammatory insults. In such instances, synthetic (exogenous) GCs such as dexamethasone and hydrocortisone (which can be more potent than endogenous GC counterparts) can be administered to aid and accelerate the resolution phase of inflammation. With regard to lung inflammation, GCs are commonly used limit inflammation during lung diseases such as asthma and ALI/ARDS.

Macrophage efferocytosis of neutrophils is enhanced in the presence of GCs such as dexamethasone and hydrocortisone in vitro [131]. Dexamethasone-treated macrophages also display structural reorganisation of the cytoskeleton and an increase in cell motility, both essential for efficient phagocytosis [132]. Furthermore, dexamethasone augmented the expression of active RAC in macrophages, a key signalling protein involved in a variety of cellular functions, including phagocytosis as well as cell motility, mitosis and wound healing [132]. GCs induce protein S-dependent efferocytosis through Mer receptor tyrosine kinase signalling, a member of the TAM 
receptor tyrosine kinase family [133, 134]. TAMs initiate signals that regulate cellular function as well as dictating the binding capacity and phagocytic clearance of apoptotic cells. TAM-deficient mice exhibit impaired efferocytosis capabilities, which are associated with several autoimmune diseases. At site of inflammation, GCs can stimulate Mer expression on phagocytes [131]. Inhibition of Mer-mediated efferocytosis in mice exacerbated LPS-induced lung injury, which was reduced by Mer-signalling upregulation via TNF $\alpha$ protease inhibitor-0 (TAPI-0), a specific inhibitor of Mer cleavage [135]. This highlights that Mer-mediated efferocytosis is a critical process which can modulate lung pathophysiology. It has been established that proteolytic cleavage from the cell membrane of phagocytes can downregulate Mer after exposure to pro-inflammatory stimuli such as LPS and bleomycin, with inhibition of this proteolytic cleavage successfully achieved via TAPI-0 blockade, which subsequently inhibits downregulation of Mer and augments efferocytosis in mouse models of LPS and bleomycin-induce lung injury [136, 137]. Deciphering the molecular mechanisms underpinning efferocytosis and its regulation via interaction with GCs will help facilitate the identification of novel therapeutic targets to promote the resolution of inflammation and tissue repair in the lung, as well as other organs. It is important to note that the efficacy of GCs during resolution if inflammation is dependent upon environmental milieu. In vitro GCs can stimulate eosinophil apoptosis; however, they are also known to delay neutrophil apoptosis. Yet during hypoxia, the GC-induced and pro-inflammatory cytokine-induced pro-survival effects upon neutrophil survival are lost [138].

Another way GCs are thought to exert and modulate their anti-inflammatory capabilities is via the expression and function of the $37-\mathrm{kDa}$ protein annexin A1 (also known as lipocortin 1), a downstream effector molecule [139]. Annexin A1 signals through a G-protein coupled receptor (GPCR) known as formyl peptide receptor 2 (FPR2; ALXR in humans), which is also the receptor for the bioactive proresolving lipid lipoxin $\mathrm{A}_{4}$ [140]. Annexin A1 binds to acidic membrane phospholipids in a $\mathrm{Ca}^{2+}$-dependent manner and is expressed in high levels in the cytoplasm of resting cells. In human neutrophils, $>60 \%$ of cytoplasmic annexin A1 is stored in gelatinase granules [141]. Following cell activation (e.g. in response to inflammatory stimuli), rapid translocation of annexin A1 to the outer membrane leaflet takes place, where this find-me signal is then secreted via different cellspecific molecular mechanisms [139]. Endogenous annexin A1 liberation from apoptotic neutrophils and GC (dexamethasone)-treated macrophages enhances macrophage efferocytosis of neutrophils in vitro [142, 143]. Levels of annexin A1 expression from circulating neutrophils and monocytes are increased in healthy volunteers after GC administration [144], with expression levels of annexin A1 also modulated during disease. In Cushing's disease (associated with elevated levels of cortisol), leukocytes exhibit markedly raised levels of intracellular annexin A1, and in Addison's disease (associated with reduced levels of cortisol), leukocytes exhibit markedly lower levels of intracellular annexin A1 compared to healthy controls [145]. Innate immune cell release of annexin A1 following GC treatment can stimulate neutrophil apoptosis and macrophage efferocytosis and inhibit neutrophil transendothelial migration [139]. In vivo data from a mouse model of acute inflammation highlight annexin A1 as a key regulator during natural and GC-induced resolution of inflammation [146]. Nonetheless, the mechanism of GC regulation of annexin A1 remains largely unclear. Incidentally, efferocytosis can also be augmented in vivo in the murine lung and in alveolar macrophages from COPD patients by treatment with statins (cholesterol-lowering drugs), specifically by treatment with lovastatin which enhances efferocytosis via RhoA inhibition (cytoskeleton regulator) [147].

\section{Successful resolution of lung inflammation}

Efferocytosis performed by resident lung phagocytes govern the successful resolution of lung inflammation and regulate normal lung structure. Professional phagocytes include alveolar macrophages, interstitial lung macrophages and lung dendritic cells, whereas non-professional phagocytes include lung epithelial cells such as alveolar and bronchial epithelial cells. Defective efferocytosis which results in an increased number of apoptotic cells is implicated in a number of lung diseases including asthma, ALI, CF and COPD and is well reviewed by [148, 149]. Furthermore, highly specialised bioactive lipids play key roles during the resolution phase of inflammation.

\section{Professional lung phagocytes}

Alveolar macrophages comprise the most abundant population of professional phagocytes within the alveolar space where they can make up $90-95 \%$ of the cell population from healthy BAL fluid. These phagocytes possess vast phagolysosomal capacity which serves to kill ingested microbes. Apoptosis of alveolar macrophages which have ingested Streptococcus pneumonia is essential for the killing and clearance of these bacteria, which contribute to resolution in a mouse model of pulmonary infection [150, 151]. Although alveolar macrophages are capable of phagocytosing a diverse array of injurious agents, at rest, rates of alveolar macrophage efferocytosis are somewhat lower than those of other tissue resident macrophages [152]. Defects in alveolar macrophage efferocytosis are attributable to several factors including diminished adhesion and via SP-A and SP-D (efficient regulators of macrophage function) activation of transmembrane receptor signal inhibitory regulatory protein alpha $(\operatorname{SIRP} \alpha)$ [153]. However, these efferocytosis defects are 
overcome via recruitment of mononuclear phagocytes during acute inflammatory scenarios such as acute pulmonary inflammation [153]. In contrast to circulating monocytes, dendritic cells and tissue resident macrophages, alveolar macrophages possess numerous apoptotic cell recognition receptors, which imply that these cells are extremely responsive to apoptotic cell death in the alveolar space [154]. Alveolar macrophages highly express all three TAM receptors, with blockade of these receptors shown to further suppress efferocytosis but not phagocytic binding [152]. The lungs can also play host to elevated numbers of interstitial macrophages, commonly observed in smokers and COPD patients. Although the efferocytosis capabilities of interstitial lung macrophages remain largely unclear, they appear to play a key role in promoting the pathogenesis of cigarette smoke-induced emphysema in mice via TNF and IL-6 release [155]. Within the lung, there are two dendritic cell subsets, and it has been demonstrated, in the murine lung, that the $\mathrm{CD}_{103^{+}}$dendritic cell subset facilitates efferocytosis and presents apoptotic cell-associated antigens to $\mathrm{CD}^{+} \mathrm{T}$ cells [156]. Similar to efferocytosis capabilities of interstitial lung macrophages, there is also a paucity of investigations upon the efferocytosis capabilities of human lung dendritic cells, which is an area that also deserves more attention.

\section{Non-professional lung phagocytes}

Recognition and subsequent efferocytosis of eosinophils by human bronchial and alveolar epithelial cells have been reported in vitro, which were augmented by dexamethasone treatment [157, 158]. Recognition of apoptotic eosinophils was found to be both lectin- and integrin-dependent [157] with apoptotic cell engulfment involving $\alpha \mathrm{v} \beta 3-$, CD36-, $\alpha \mathrm{v} \beta 5$ - and PS receptor-mediated events [158]. These findings therefore imply a non-passive role for the airway epithelium during eosinophilic-dominant inflammation in asthma. More recently, in transgenic mouse models of allergic airway inflammation, the Ravichandran group were able to demonstrate RAC1-dependent efferocytosis of airway epithelial cells by bronchial epithelial cells, which resulted in liberation of antiinflammatory cytokines [159] (see Table 1 for an overview of anti-inflammatory cytokines and associated bioactivities). Incidentally, inducible deletion of RAC1 expression in mouse airway epithelial cells resulted in impaired efferocytosis and generation of an atypical antiinflammatory cytokine profile in bronchial epithelial cells [159]. Yet, of present, there remains a distinct lack of investigations attempting to manipulate efferocytosis capabilities in lung epithelial cells in current models of airway inflammation. Facilitation of such investigations could help unearth novel therapeutic approaches for the treatment of various inflammatory lung diseases.

\section{Pro-resolving bioactive lipids}

Lipoxygenase (LOX)-dependent enzymatic conversion of polyunsaturated fatty acid (PUFA) substrates to PUFAderived mediators is another important biochemical process which is key to modulating inflammation $[5,160]$. PUFAs are released from the cell membranes of activated cells such as neutrophils, monocytes/macrophages, lymphocytes and eosinophils, then are enzymatically converted to specialised proresolution lipid mediators, which vary in structure and function [161]. These pro-resolving lipid mediators include lipoxins $\left(\mathrm{A}_{4}\right.$ and $\left.\mathrm{B}_{4}\right)$, $\mathrm{D}$ - and E-series resolvins, protectins and maresins and are active from picogram to nanogram scales. These bioactive lipids often possess dual antiinflammatory and pro-resolution bioactivities (see Table 2 for overview), which are excellently reviewed by the Serhan group [21, 162, 163]. In clinic, pharmacological inhibitors including those that target certain lipoxygenases are used due to their ability to suppress adverse events which accompany inflammation; however, these inhibitors can also impair endogenous production of other bioactive lipids [164-166]. Contrastingly, aspirin and the glucocorticoid dexamethasone can initiate endogenous anti-inflammatory pathways via activation of the lipoxin $\mathrm{A}_{4}$ receptor AXLR/formyl peptide receptor like-1 receptor (FPRL1) [140], a GPCR which is now termed AXLR/FPR2 [167]. These pro-resolving bioactive lipids are implicated in a number of inflammatory lung diseases, including asthma, cystic fibrosis, interstitial lung disease, aspirin-exacerbated respiratory disease, COPD and emphysema [161].

\section{Lipoxins and resolvins}

At sites of inflammation, the PUFA arachidonic acid (ADA) can be metabolised to prostaglandins and leukotrienes (such as $\mathrm{LTB}_{4}$ ), but it is also converted to a family of pro-resolving bioactive lipids termed lipoxins, which can suppress leukotriene-induced inflammation [168]. Presently, lipoxins are the most studied family of pro-resolution lipids and their levels considerably increase during the resolution phase of inflammation [5]. During airway inflammation, enzymatic hydrolysis via neutrophil 5-LOX and epithelial 15-LOX activity leads to lipoxin $\mathrm{A}_{4}$ and $\mathrm{B}_{4}$ biosynthesis [4]. Additional lipoxin $\mathrm{A}_{4}$ and $\mathrm{B}_{4}$ biosynthesis can occur via platelet and neutrophil interactions (via platelet $12-\mathrm{LOX}$ ) such as in the vasculature [169] as well as by various cell types including neutrophils, eosinophils and alveolar macrophages, albeit to a lesser extent $[5,169,170]$. As well as ADA, additional PUFAs are present at sites of inflammation such as docosahexaenoic acid (DHA) and eicosapentaenoic acid (EPA), which can be enzymatically converted to D- and E-series resolvins, respectively. During vascular inflammation, DHA is converted by aspirinacetylated endothelial cell-derived cyclooxygenase-2 (COX- 
Table 1 Anti-inflammatory bioactivities of various cytokines

\begin{tabular}{ll}
\hline Cytokine & Main source(s) \\
\hline IL-1ra & $\begin{array}{c}\text { Monocytes/macrophages, T cells, } \\
\text { B cells and dendritic cells }\end{array}$ \\
IL-2 & TH cells \\
& \\
& \\
IL-4 & T cells (TH2), B cells, mast cells \\
& and basophils \\
& \\
& \\
& \\
IL-6 & T cells, B cells, neutrophils, \\
& monocytes/macrophages, \\
& PMN leukocytes and fibroblasts \\
IL-10 & Monocytes/macrophages, \\
& T cells (TH2) and B cells
\end{tabular}

IL-11 Stromal cells, fibroblasts, epithelial cells and osteoblasts

IL-13 T cells (TH2)

IL-22 T cells, NK cells and dendritic cells,

IL-27

T cells, monocytes, neutrophils, NK cells, mast cells and bronchial epithelial cells

IL-35 Regulatory B and T cells

IL-37 Macrophages and epithelial cells

IL-38 PBMCs

TGF $\beta \quad$ T cells, monocytes/macrophages, neutrophils, platelets, alveolar epithelial/endothelial cells and fibroblasts

IFN $\alpha \quad$ Monocytes/macrophages, PMN leukocytes, plasmacytoid dendritic cells, alveolar epithelial cells and fibroblasts
Major anti-inflammatory bioactivities

Specifically inhibits the activity of pro-inflammatory IL-1 $\alpha$ and IL-1 $\beta$

Modulates cellular and humoral responses during chronic inflammation, increases $\mathrm{T}$ cell proliferation, lymphokine secretion and augments expression of MHC class II molecules

Inhibits generation of monocyte-derived pro-inflammatory cytokines IL-1, IL-6, IL-8, TNF and MIP- $1 \alpha$; decreases macrophage cytotoxic activity and NO production; stimulated IL-1 ra synthesis; augments MHC class II expression on B cells; and promotes B cell, T cell and mast cell development

Inhibits pro-inflammatory TNF, IL-1, GM-CSF, IFN $\gamma$ and MIP-2 generation and stimulates synthesis of glucocorticoids and IL-1ra

Inhibits generation of monocyte/macrophage-derived pro-inflammatory TNF, GM-CSF, MIP- $1 \alpha$, MIP- $2 \alpha$, IL-1, IL-6, IL-8 and IL-12 and also attenuates pro-inflammatory cytokine generation in neutrophils and mast cells

Inhibits generation of pro-inflammatory IL-1 and TNF generation from macrophages and stimulates $\mathrm{TH} 2$ cell responses

Inhibits generation of pro-inflammatory IL-1 $\beta$, IL-6, IL-8 and TNF generation by monocytes and augments differentiation and proliferation of monocytes and B cells

Induces proliferative and anti-apoptotic pathways and production of AMPs which serve to block tissue destruction and support tissue repair and modulates tissue responses during intestinal inflammation

Regulates T cell responses and differentiation and limits pro-inflammatory cytokine production

Stimulates T cell proliferation and anti-inflammatory IL-10 and TGF $\beta$ generation

Decreases generation of pro-inflammatory cytokines

Decreases generation of IL-8 and T cell cytokines

Inhibits leukocyte adhesion and monocyte/macrophage pro-inflammatory cytokine generation and promotes wound healing/angiogenesis

Induces anti-inflammatory IL-1ra and IL-10 generation and inhibits pro-inflammatory IL-1, IL-8 and TNF generation

IL-1 ra interleukin-1 receptor agonist, TH T helper, $M H C$ major histocompatibility complex, MIP-1 $\alpha$ macrophage inflammatory protein-1 alpha, $N O$ nitric oxide, $P M N$ polymorphonucleated, AMPs anti-microbial peptides, PBMCs peripheral blood mononucleated cells

2) via neutrophil LOX activity, which leads to hydrolysis of D-series resolvins [161]. In a similar inflammatory scenario, EPA is converted to E-series resolvins by aspirin-acetylated endothelial cell-derived COX-2, where biosynthesis of Eseries resolvins involves direct transformation of unstable intermediates of EPA by activated leukocytes [161]. The GPCR AXLR/FPR2 serves as the receptor for lipoxin $\mathrm{A}_{4}$ and resolvin D1 [171, 172], which can also be activated by annexin A1 via glucocorticoid induction [140]. Humans express ALXR/FPR2 in leukocytes and tissue resident cells [171] with receptor expression modulated by local inflammatory mediators. Resolvin D1 also binds to another GPCR, namely, GPR32, which is also known as the resolvin D1 receptor (DRV1) and expressed by leukocytes [173]. However, 
Table 2 Specialised bioactive lipids which promote the resolution of inflammation

\begin{tabular}{|c|c|c|}
\hline $\begin{array}{l}\text { Bioactive } \\
\text { lipid }\end{array}$ & $\begin{array}{l}\text { Main } \\
\text { source }\end{array}$ & Major anti-inflammatory and pro-resolution bioactivities \\
\hline Lipoxins & ADA & \\
\hline Lipoxin $\mathrm{A}_{4}$ & & $\begin{array}{l}\text { Neutrophils reduce chemotaxis/recruitment/transendothelial/epithelial migration, epithelial } \\
\text { cell interactions, number of apoptotic neutrophils, } 2^{-} \text {generation and degranulation } \\
\text { Monocytes stimulate chemotaxis/adhesion and reduce peroxynitrite generation } \\
\text { Macrophages enhanced efferocytosis of neutrophils } \\
\text { Eosinophils reduce migration/chemotaxis and generation of IL-5 and eotaxin } \\
\text { NK cells reduce cytotoxicity and increase granulocyte apoptosis } \\
\text { Dendritic cells reduce generation of IL-12 } \\
\text { Epithelial cells reduce the release of IL-6 and IL-8 } \\
\text { Endothelial cells reduce ROS generation and VEGF-induced migration } \\
\text { Other decreases vascular leakage and adherent capabilities of leukocytes }\end{array}$ \\
\hline Lipoxin $\mathrm{B}_{4}$ & & $\begin{array}{l}\text { Leukocytes modulate the adherence and motility of neutrophils/monocytes and inhibit } \\
\text { neutrophil infiltration and stimulate macrophage recruitment }\end{array}$ \\
\hline D-resolvins & DHA & \\
\hline Resolvin D1 & & $\begin{array}{l}\text { Neutrophils reduce recruitment and transmigration } \\
\text { Macrophages stimulate/augment phagocytosis of apoptotic cells and allergens, induce } \\
\text { M2 macrophage phenotype and reduce LPS-induced TNF release } \\
\text { Other reduces resolution interval, oxidative stress, pro-inflammatory cytokines in } \\
\text { BAL fluid and levels of prostaglandins/leukotrienes and augment microbial clearance }\end{array}$ \\
\hline Resolvin D2 & & Leukocytes reduce neutrophil infiltration and leukocyte-endothelial cell interactions \\
\hline Resolvin D3 & & $\begin{array}{l}\text { Leukocytes reduce neutrophil transmigration and augment macrophage } \\
\text { phagocytosis/efferocytosis }\end{array}$ \\
\hline Resolvin D4 & & $\begin{array}{l}\text { Leukocytes reduce neutrophil infiltration and augment macrophage efferocytosis of } \\
\text { neutrophils and phagocytic clearance of Staphylococcus aureus } \\
\text { Other augments fibroblast efferocytosis of neutrophils }\end{array}$ \\
\hline E-resolvins & EPA & \\
\hline Resolvin E1 & & $\begin{array}{l}\text { Neutrophils reduce } \mathrm{O}_{2}^{-} \text {generation and transendothelial/epithelial migration } \\
\text { Monocytes decrease cell number } \\
\text { Macrophages augment efferocytosis of neutrophils } \\
\text { Eosinophils/lymphocytes reduce recruitment } \\
\text { Dendritic cells reduce migration and IL-12 generation } \\
\text { Other modulates the production of chemokines/cytokines and stimulates anti-apoptotic } \\
\text { signals and reparative processes in inflamed tissues }\end{array}$ \\
\hline Resolvin E2 & & $\begin{array}{l}\text { Leukocytes modulate neutrophil chemotaxis, augment phagocytosis and generation of } \\
\text { anti-inflammatory cytokines, efficiently downregulate the surface expression of integrins } \\
\text { and reduce responses to PAF }\end{array}$ \\
\hline Resolvin E3 & & Neutrophils reduce infiltration \\
\hline Protectins & DHA & \\
\hline Protectin D1 & & $\begin{array}{l}\text { Neutrophils reduce infiltration, transmigration and TNF/IFN } \gamma \text { generation } \\
\text { Macrophages modulate function and stimulate efferocytosis of PMN leukocytes } \\
\text { Other modulates chemokine/cytokine production and migration of T cells and reduces } \\
\text { eosinophil chemotaxis/adhesion }\end{array}$ \\
\hline Maresins & DHA & \\
\hline Maresin 1 & & $\begin{array}{l}\text { Neutrophils reduce numbers in peritonitis exudates } \\
\text { Macrophages augment phagocytic capabilities } \\
\text { Other reduces PMN leukocyte transendothelial cell migration and dust-induced cytokine } \\
\text { production in bronchial epithelial cells and aids tissue regeneration }\end{array}$ \\
\hline
\end{tabular}

Source: $[193,194]$

$A D A$ arachidonic acid, $\mathrm{O}^{-}$superoxide anion radical, $V E G F$ vascular endothelial growth factor, EPA eicosapentaenoic acid, $D H A$ docosahexaenoic acid, $B A L$ bronchial alveolar lavage, $P A F$ platelet-activating factor, $P M N$ polymorphonucleated 
due to lack of GPR32 mobilisation from human neutrophils, the pro-resolution activities of resolvin D1 are brought about primarily by ALXR/FPR2 signalling pathways, which have confirmed that mice are lacking the ALXR/FPR2 receptor [174]. Resolvin E1 can bind to additional GPCRs, namely, the chemokine receptor-like 1 (CMKLR1) receptor and $\mathrm{LTB}_{4}$ receptor 1 (BLT1) expressed by polymorphonucleated (PMN) leukocytes [175].

\section{Protectins and maresins}

Protectins are generated via a 15-LOX-dependent manner which catalyses the conversion of DHA to protectin D1 via an epoxide intermediate [176]. Additionally, aspirin can initiate protectin biosynthesis from DHA via COX-2 acetylation [177]. The pro-resolving bioactions of protectin D1 are known to be cell-specific; therefore, it is likely that such interactions are mediated by one or more specific receptors. However, protectin 1-specific receptors remain to be identified [161]. Somewhat more recently, maresins (derived from macrophages) have been discovered, which are another family of pro-resolving bioactive lipids [178]. Akin to protectins and D-series resolvins, maresins are also derived from DHA. However, biosynthesis of maresin 1 occurs via a novel epoxide intermediate, which also enhances the conversion of macrophages from an M1 to M2 phenotype, with M2 macrophages able to produce elevated levels of this pro-resolving lipid mediator from the epoxide intermediate compared to M1 macrophages [179]. Importantly, in terms of pro-resolution, maresin 1 is also able to increase macrophage efferocytosis and aid tissue regeneration [178, 180]. Identification of maresin 1-specific receptors is yet to transpire; however, it is apparent that specific GPCRs are involved [180].

\section{Bioactive lipids in lung inflammation}

Impaired generation of these pro-resolving lipid mediators during airway inflammation can lead to chronic inflammatory lung diseases. Decreased lipoxin formation has been described in severe/uncontrolled asthma, cystic fibrosis, aspirin-exacerbated respiratory disease and sclerodermainterstitial lung disease [181-184]. During severe/ uncontrolled asthma, dysregulated expression of lipoxin biosynthetic genes is partly responsible for the decreased production of lipoxins (see review by Levy et al. [185]). Elevated levels of DHA are found in the airway mucosa of heathy individuals; however, during asthma and cystic fibrosis, mucosal levels of DHA are reduced [186]. Resolvins E1 and D1 can enhance the resolution of allergic airway inflammation in mouse models of asthma [187, 188]. Resolvin E1 reduced the numbers of macrophages, eosinophils and lymphocytes present in BAL fluid as well as improving airway hyperreactivity and airway mucus metaplasia postinhalation of methacholine in mice [189]. Specifically, resolvin E1 enhances the resolution of allergic airway inflammation via reduction in IL-6, IL17 and IL-23 production in the murine lung, with proresolution assisted via increased generation of IFN $\gamma$ and lipoxin $\mathrm{A}_{4}$ in the lungs of mice treated with resolvin $\mathrm{E} 1$ [189]. Recently, resolvin D4 has been identified in human tissues and confirmed to have potent pro-resolving activities during murine $S$. aureus infections [190, 191]. However, the precise role of resolvin D4 during lung inflammation remains to be established. Akin to lipoxin levels during severe/ uncontrolled asthma, a reduction in protectin $\mathrm{D} 1$ levels is also observed during acute asthma exacerbations [192]. Protectin D1 can also reduce allergic airway responses in a mouse model of asthma where intravenous administration of protectin D1 (prior to aeroallergen challenge) results in attenuation of eosinophil infiltration and pro-inflammatory cytokine release [192]. Furthermore, postallergen challenge (once pulmonary inflammation has been established), protectin D1 is able to exert pro-resolution properties which accelerate the resolution of allergic airway inflammation [192]. Taken together, the above evidence indicates that these bioactive lipids are key effectors of pro-resolution circuits during lung inflammation and that impairment in their endogenous levels contributes to several inflammatory lung diseases. For thorough review of the roles played by pro-resolution bioactive lipids during lung inflammation, refer to [161].

\section{Dysregulated/impaired resolution of lung inflammation}

\section{Neutrophil-dominant inflammation}

As the most abundant cells, and in many ways the bluntest instruments of the immune armoury, it is perhaps unsurprising that neutrophilic inflammation is a hallmark of numerous inflammatory lung conditions. Furthermore, the lungs are prime sites for inflammation and injury as neutrophils persist in the lung far longer than other organs [195]. The first responders to both endogenous and exogenous stimuli, their role in acute disorders, are without question, yet they are also implicated in the pathogenesis of numerous chronic conditions, suggesting a failure of the normal mechanisms by which resolution proceeds. Below, we use several demonstrative conditions to illustrate the mechanisms of neutrophilic inflammation, resolution and development of chronicity.

\section{Pneumonia}

As a significant burden of morbidity and mortality both within the UK and the wider world, pneumonia is the acute inflammatory response to infection of the lower respiratory tract that is visible on a chest $\mathrm{X}$-ray. It occurs in response to a variety of pathogens, most commonly bacteria and viruses, and is usually triggered by recognition of conserved 'foreign' receptors. 
Where the host response is successful in containing and engulfing the responsible pathogen, infection remains localised and the lung may heal without sequelae. Acute failure of this process results in disseminated infection, which may ultimately lead to death. In the intermediate to long term, failure of successful sequestration and resolution predisposes to empyema, abscess formation and bronchiectasis. Despite better understanding of the underlying mechanisms of inflammation and injury, the mainstay of treatment for pneumonia remains anti-microbials. Unfortunately, there remain a subset of patients in whom even a combination of host defence and antibiotics fail to control infection and who go on to develop multi-organ failure (see below). In recent years, there has been more interest in exploring the role of modulating the immune response in severe pneumonia, and numerous different drugs have shown some potentials in improving outcomes.

Streptococcus pneumoniae is the most commonly implicated pathogen in community-acquired pneumonia (CAP) and can result in a spectrum of disease severity. Streptococcal infection is associated with dense neutrophilic inflammation and activation of the coagulation cascade, via the thrombin receptor, proteinase-activated receptor 1 (PAR-1). Numerous PAR-1 antagonists have been developed, and animal models suggest that suppression of coagulation activation via this pathway can reduce neutrophil airway load, inflammatory cytokine production and alveolar leak without compromising bacterial clearance [196]. Furthermore, proof of principal research suggests that existing anti-platelet agents well established in the management of cardiovascular disease may yet improve outcomes in pneumonia by reducing activation of the coagulation cascade and thereby progression to ALI and ARDS [197]. Activated protein C (APC) is an endogenous anti-inflammatory and anticoagulant chemokine that is implicated in the prevention of disseminated infection and source control. It has recently been highlighted that in animal models of streptococcal pneumonia, overexpression of APC reduces bacterial spread to other organs and neutrophilic inflammation at the primary infection site [198]. As well as exploration of the pathways involved in the acute inflammatory response, there has been growing interest in drugs with an established role in the management of chronic lung diseases, such as macrolides. Macrolides have long been in favour as they exhibit both anti-bacterial and antiinflammatory properties and are useful in conditions where bacterial colonisation is a hallmark, including diffuse pan-bronchiolitis, cystic fibrosis and bronchiectasis. A recent pilot study highlighted a trend towards reduced circulating proinflammatory cytokine levels in patients with CAP treated with macrolides vs. those treated with other classes of anti-microbials, particularly at 5-7 days postinfection [199]. In the past decade, it has been increasingly recognised that as well as reducing lipid burden and modifying cardiovascular disease, HMG Co-A reductase inhibitors (statins) have hitherto unappreciated anti-inflammatory effects that are potentially harnessable for management of inflammatory disease. A recent trial suggested that atorvastatin reduced cough severity in stable bronchiectasis with associated increase in apoptotic neutrophils seen in sputum, and there is renewed interest in their role in modulating acute inflammatory conditions [200]. A recent systematic review examined a number of studies exploring the role of statins in CAP and concluded that they modulate neutrophil response, reduce circulating cytokine burden and potentially impact mortality [201].

Neutrophil longevity is a key determinant of the inflammatory response and is an obvious target in the search for novel antiinflammatory agents. In the setting of infection, the challenge is the safe depletion of neutrophil number to a level that is able to ameliorate short- and long-term morbidities without compromising host defence and predisposing to systemic infection. There is evidence in numerous acute and chronic lung conditions, including CAP, that failure of timely neutrophil apoptosis contributes to morbidity [202]. Cyclin-dependent kinase inhibitors (CDKis) are a group of drugs that are being extensively researched for their ability to arrest cell cycle progression and induce apoptosis even in terminally differentiated cells such as neutrophils via downregulation of Mcl-1, and there are now several studies which demonstrated their potential as safe and effective modulators of inflammation [203-205].

\section{$A R D S$}

Multi-organ dysfunction syndrome (MODS) is a frequently fatal condition caused by an overwhelming inflammatory insult that results in a paradoxically unhelpful aggressive mucosal response. ARDS is the respiratory component of this disorder and results from a pathological reaction known as diffuse alveolar damage, which occurs secondary to rampant neutrophilic inflammation [206]. There are many causes of ARDS, including sepsis, shock, trauma and gastric aspiration [207, 208]. Progression to ARDS is a marker of severe sepsis and is associated with poor outcomes. Therapy for MODS remains largely supportive, but there is growing interest in the role of immune modulation as an adjunct to anti-biotic or other therapy to dampen the hyperactive immune response that ultimately leads to severe impairment of gas exchange and respiratory failure. Mortality in ARDS correlates with neutrophil number and levels of circulating pro-inflammatory cytokines, suggesting that harnessing the inflammatory response may be the key to improving outcomes [209, 210].

Despite ongoing controversy, glucocorticoids remain the best studied anti-inflammatory strategy in ARDS. There is some evidence to suggest that given early in disease course, intravenous steroids reduce requirement for mechanical ventilation, length of ITU stay and improve oxygenation, with a modest effect on mortality [211-214]. Such success is, however, only likely to outweigh potential complications in the setting of vigilant surveillance for nosocomial infection and 
eschewal of neuromuscular blockade due to the potential complications of steroid treatment. Furthermore, it has been suggested that if left to later time points, i.e. $>14$ days postonset, steroid administration may cause a paradoxical increase in mortality [211]. Consequently, glucocorticoid therapy remains to be proven as an effective therapy for ARDS and is not recommended for treatment unless it is known to be secondary to a steroid-sensitive insult. Early studies in animal models suggest that macrolide anti-biotics may demonstrate efficacy in management of ARDS [215, 216]. Although this is supported by an observational study that highlights a trend towards reduced mortality with macrolide treatment, the evidence remains insufficiently robust to support their use as a routine management option [217, 218]. Perhaps almost as enlightening as those therapies that have demonstrated promise are those which despite good biochemical rationale have failed to prove clinically efficacious. Despite the known role of cyclo-oxygenase-derived metabolites in sepsis and its sequelae, use of non-steroidals has historically been demonstrated not to lead to a reduction in sepsis-associated ARDS [219].

\section{Cystic fibrosis}

$\mathrm{CF}$ is the most common life-limiting autosomal recessive condition in Caucasians, with an incidence of 1 in 2500 . Caused by loss of function mutations of cystic fibrosis transmembrane conductance regulator (CFTR), an epithelial chloride channel, it is a heterogenous multi-system inflammatory disorder of which the major clinical manifestations are severe, progressive bronchiectasis and exocrine pancreatic insufficiency. The classical pathophysiological explanation for CF lung disease is the 'low-volume hypothesis', whereby abnormal airway surface electrochemical gradients secondary to loss of CFTR result in increased uptake of water and extracellular cations [220]. The resultant dehydration of airway surface liquid promotes mucus hypersecretion, inhibits mucociliary clearance and disables cationic host defence peptides, leading to incessant cycles of sinopulmonary infections that eventually progress to chronic inflammation with airway remodelling. Once structural lung disease has developed in $\mathrm{CF}$, it is rare for it to regress, and consequently, there is a desperate need to develop effective early management options to reduce long-term morbidity [221].

In recent years, there has been a move to explore the role of aberrant immune function in CF patients, as it is evident that there are non-CFTR determinants of (lung) disease severity and numerous hints of abnormal inflammatory responses. The unusual susceptibility of CF patients to 'low-virulence' pathogens, such as P. aeruginosa and Burkholderia cepacia, increased incidence of allergic airway disease, and growing evidence of a 'CF-related enteropathy' and systemic inflammation are to name but a few [222-224]. Despite decades of research, until recently, there has been very little progress in development of new treatment options for $\mathrm{CF}$, although promising drugs directly restoring the CFTR function have recently become available for a small subset of patients [225]. For the remainder of the CF population, perhaps the best hope lies in the development of safe and effective anti-inflammatory agents that can be used synergistically with anti-biotic therapies to prevent the establishment of chronic inflammation and airway damage.

A number of groups have demonstrated intrinsic failure of the innate immune system in $\mathrm{CF}$, and debate continues over whether this is a result of a hitherto unappreciated role of CFTR in neutrophil function or secondary to a chronic inflammatory environment in CF adults. Delayed neutrophil apoptosis, aberrant phagolysosomal destruction of Pseudomonas and excess IL-8 production have all been described in CF patients and offer an array of therapeutic targets [223, 226, 227]. As discussed above, there is much hope that CDKis can offer a novel approach to immune modulation in inflammatory disorders as their role in managing non-malignant disorders is explored. There is preliminary evidence that CDKis can correct delayed apoptosis in CF neutrophils, offering hope of correcting the inflammatory response and perhaps increasing the efficacy of antimicrobials in potentiating clearance of established airway pathogens [227]. Indeed, with development of novel water-soluble CDK inhibitors, the option of nebulised therapy remains open and may reduce systemic effects whilst concentrating efficacy. As well as a paradoxical failure to clear pathogens, the persistence of neutrophils in the $\mathrm{CF}$ airway results in excess PMN-derived proteases, which not only damage respiratory epithelia directly but also reduce the efficiency of phagocytic clearance [228, 229].

Conventional anti-inflammatory strategies have historically been trialled in $\mathrm{CF}$ patients but remain limited by significant adverse effects, and they remain out of favour in routine clinical practice [230, 231]. There has been little exploration of the role of 'topical' traditional anti-inflammatories such as nebulised non-steroidal anti-inflammatory drugs (NSAIDs), although this route may offer a safe and more effective opportunity to ameliorate lung inflammation whilst minimising systemic effects [232]. Inhaled corticosteroids are generally reserved for those patients with concurrent airway hyperreactivity as they demonstrate a more steroid-responsive airway inflammatory infiltrate. Several groups have demonstrated increased $\mathrm{LTB}_{4}$ levels in the CF airway, and there has been some success in using montelukast, a leukotriene receptor antagonist well established in the management of asthma, to reduce respiratory symptoms in CF patients $[233,234]$. Perhaps unsurprisingly, given the prevalence of microbial colonisation, macrolides have a long history in CF lung disease. Their role is generally accepted to be related to both their anti-inflammatory properties as well as delayed anti-microbial effects, which reduce pathogen burden [235-238]. Unfortunately, there is recent evidence to suggest that longterm macrolide use is associated with the increasing incidence of multi-resistant atypical mycobacterial infections in CF patients, which may ultimately limit their use [239]. One of the 
problems with novel agent development is the protracted period from bench to bedside, and as such, there is great interest in exploring alternative uses for drugs with well-established safety and tolerability profiles. Statins, long favoured for their role in serum lipid modulation, are now known to exhibit broader antiinflammatory properties, and the potential implications of this are currently being explored in a variety of conditions. IL-8 is known to be abundant in CF serum, and it has recently been demonstrated that fluvastatin is able to reduce IL- 8 levels and may ultimately help to suppress systemic inflammation [240].

\section{Eosinophil-dominant inflammation (asthma)}

Eosinophils are important during allergic airway inflammation. The combined injurious effects resulting from high numbers of infiltrating eosinophils, delayed eosinophil apoptosis and impaired efferocytosis can cause chronic inflammatory lung disease, such as asthma. Asthma is a spectrum of conditions defined by the common pathology of reversible airway obstruction and hypersensitivity of the respiratory mucosa to environmental antigens. Most commonly, it occurs as part of an allergic syndrome of atopic disorders, though may occur in isolation. Asthma patients develop sensitivity to environmental antigens such as animal dander and plant material and on exposure to those antigens, develop a type 1 allergic response resulting in bronchoconstriction, wheeze, cough and mucus hypersecretion that lead to airflow limitation.

Affecting approximately $10 \%$ of UK adults, asthma is a common disorder of multi-factorial origins, with research indicating that both genetics and the environment have a significant role to play. In predisposed individuals, 'normal' environmental antigens transmigrate through the airway epithelia and are presented to naïve $\mathrm{T}$ cells, which trigger activation of IgE production by B cells. IgE interacts with receptors on the surface of tissue resident mast cells, and further exposure to the antigen results in IgE cross-linkage with cell activation. The resultant mast cell degranulation causes release of mediators including histamine, LTB 4 , IL-8 and IL-10 and TNF, precipitating an acute inflammatory response. The late-phase asthmatic response classically occurs $6-9 \mathrm{~h}$ after antigen exposure and occurs secondary to the persistent secretion of cytokines, e.g. IL-5, GM-CSF and IL-3, which promote eosinophil migration, persistence and longevity in the lungs and form the bass of persistent airway inflammation in asthma patients.

The mainstay of asthma treatment is glucocorticoids, generally administered as inhaled preparations, which blunt the inflammatory response and trigger eosinophil apoptosis. This therapy, with adjunct bronchodilators, is sufficient to control symptoms in the majority of patients but lacks subtlety and is significantly limited by toxicity. Perhaps unsurprisingly, there remains a subset of patients who fail to respond to this approach and have persistently uncontrolled symptoms that may ultimately lead to airway remodelling. Consequently, there is a need for novel, specific inhibitors of eosinophilic inflammation in the lung, which can sufficiently control symptoms and display minimal systemic toxic effects [241]. There has been good success with the use of adjunct leukotriene receptor antagonists in the management of moderate-severe asthma, which selectively inhibit the pro-inflammatory effects of leukotrienes, highlighting that the principle of targeted therapies is sound [242].

Delayed eosinophil apoptosis and thereby persistence in the airway remains a core pathological feature of asthma and is one of the targets of steroid therapy. Recent in vitro and murine studies have demonstrated that as in neutrophils, CDK inhibitors are able to induce apoptosis of both circulating and inflammatory eosinophils via downregulation of Mcl1 , although the significance of this in the clinical setting remains unclear [243-245]. A recent study examining novel modulators of eosinophil apoptosis has highlighted that hydrogen peroxide induces cell death and accelerates resolution of airway inflammation in a caspase-dependent manner, as well as accelerating recovery of lung function [246]. As previously discussed, in recent years, there has been much emphasis on the role of endogenous lipid mediators of resolution, e.g. lipoxins, resolvins and protectins, and the potential role they may play in ameliorating the harmful response in inflammatory conditions [69]. Resolvin D1, one such mediator, and its counterpart aspirin-triggered resolvin D1 have been shown to significantly reduce airway eosinophilia and mucus hypersecretion via reduction of IL-5 degradation [188]. Lipoxin $\mathrm{A}_{4}$ has been reported to downregulate eosinophil responses via the suppression of activation by GM-CSF [247]. Its functionally related, though structurally distinct counterpart lipoxin $\mathrm{B}_{4}$, promotes resolution of allergic resolution in upper and lower airways via reduced eosinophil chemotaxis and mast cell degranulation, emphasising the potential for therapeutic harnessing of these pathways in eosinophilic airway disorders [248]. Flavones are a recently described group of polyphenolic compounds with potential anti-inflammatory and antimalignant properties, which have been the subject of much research interest. The flavone wogonin has been shown to modulate granulocyte apoptosis via suppression of Mcl-1 and CDK-9, both in vivo and in vitro, therefore highlighting a potential role for flavones in atopic disorders [249-251].

\section{Conclusion}

In the lung, prompt resolution of acute inflammatory responses occurs regularly, aiding to preserve a healthy state within the host. In most cases, this process is instigated by neutrophils, but in certain scenarios, eosinophils can dominate; where in either case, these granulocytes respond to noxious respiratory stimuli such as airborne pathogens, allergens and foreign particles. The outcome of acute inflammation in the lung is regulated by a balance between the presence of different sets of mediators and 
specific receptors. These mediators and receptors either serve to exacerbate the inflammatory response, which can lead to chronic lung inflammation and the onset of diseases such as ARDS, CF, COPD and asthma, or they can dampen inflammation and contribute to returning the lung to a healthy state via pro-resolution and pro-reparative processes. We have attempted to report the current understandings with regard to mechanisms central to controlling the resolution of lung inflammation and injury. Clearly, enhanced efferocytosis of apoptotic neutrophils/eosinophils performed by anti-inflammatory and/or pro-resolution macrophages, who in turn shut down their release of pro-inflammatory stimuli and increase their release of pro-resolution/reparative mediators, remains a key process for successful resolution of inflammation and repair. More recently, however, it has become evident that specialised bioactive lipid mediators belonging to the lipoxin, resolvin, protectin and maresin families can also modulate inflammation by contributing to the pro-resolution process. The biological actions of pro-resolving lipids are stereospecific, receptormediated and extremely potent even at picogram and nanogram concentrations [161]. Additionally, these pro-resolving lipids selectively interact with key cell types involved in innate immune defence, where they can have cell-type specific actions upon neutrophils, macrophages and endothelial cells [161]. In the lung, such actions include termination of leukocyte infiltration; return to normal vascular permeability via concomitant reduction in pulmonary edema, neutrophil apoptosis, non-inflammatory infiltration of monocytes/ macrophages and macrophage efferocytosis of such neutrophils; and macrophage removal of respiratory pathogens and necrotic remnants. These actions all assist in the successful resolution of lung inflammation and injury to return the lungs to normal homeostasis and health. Further identification of mediators and the mechanisms by which they contribute to resolution of lung inflammation will help provide novel therapeutic strategies for the treatment of lung disease and injury.

Acknowledgments The authors acknowledge funding from the Medical Research Council, UK (MR/K013386/1), for C.T.R./A.G.R., and from the Wellcome Trust (WT096497) for D.A.D.

\section{Compliance with ethical standards}

Conflict of interests The authors declare that they have no conflict of financial interests.

Open Access This article is distributed under the terms of the Creative Commons Attribution 4.0 International License (http:// creativecommons.org/licenses/by/4.0/), which permits unrestricted use, distribution, and reproduction in any medium, provided you give appropriate credit to the original author(s) and the source, provide a link to the Creative Commons license, and indicate if changes were made.

\section{References}

1. Leitch AE, Duffin R, Haslett C, Rossi AG (2008) Relevance of granulocyte apoptosis to resolution of inflammation at the respiratory mucosa. Mucosal Immunol 1:350-363. doi:10.1038/mi. 2008.31

2. Nathan C (2002) Points of control in inflammation. Nature 420: 846-852. doi:10.1038/nature01320

3. Nathan C, Ding A (2010) Nonresolving inflammation. Cell 140: 871-882. doi:10.1016/j.cell.2010.02.029

4. Serhan CN, Brain SD, Buckley CD et al (2007) Resolution of inflammation: state of the art, definitions and terms. FASEB J 21:325-332. doi:10.1096/fj.06-7227rev

5. Levy BD, Clish CB, Schmidt B et al (2001) Lipid mediator class switching during acute inflammation: signals in resolution. Nat Immunol 2:612-619. doi:10.1038/89759

6. Bannenberg GL, Chiang N, Ariel A et al (2005) Molecular circuits of resolution: formation and actions of resolvins and protectins. J Immunol 174:4345-4355

7. Serhan CN, Chiang N (2008) Endogenous pro-resolving and antiinflammatory lipid mediators: a new pharmacologic genus. Br J Pharmacol 153:S200-S215. doi:10.1038/sj.bjp.0707489

8. Buckley CD, Gilroy DW, Serhan CN (2014) Proresolving lipid mediators and mechanisms in the resolution of acute inflammation. Immunity 40:315-327. doi:10.1016/j.immuni.2014.02.009

9. Michlewska S, McColl A, Rossi AG et al (2007) Clearance of dying cells and autoimmunity. Autoimmunity 40:267-273. doi: 10.1080/08916930701357208

10. Poon IKH, Lucas CD, Rossi AG, Ravichandran KS (2014) Apoptotic cell clearance: basic biology and therapeutic potential. Nat Rev Immunol 14:166-180. doi:10.1038/nri3607

11. Motwani MP, Gilroy DW (2015) Macrophage development and polarization in chronic inflammation. Semin Immunol 27:257266. doi:10.1016/j.smim.2015.07.002

12. Persson C, Uller L (2010) Transepithelial exit of leucocytes: inflicting, reflecting or resolving airway inflammation? Thorax 65:1111-1115. doi:10.1136/thx.2009.133363

13. Gilroy DW, Lawrence T, Perretti M, Rossi AG (2004) Inflammatory resolution: new opportunities for drug discovery. Nat Rev Drug Discov 3:401-416. doi:10.1038/nrd1383

14. Duffin R, Leitch AE, Fox S et al (2010) Targeting granulocyte apoptosis: mechanisms, models, and therapies. Immunol Rev 236: 28-40. doi:10.1111/j.1600-065X.2010.00922.x

15. Alessandri AL, Sousa LP, Lucas CD et al (2013) Resolution of inflammation: mechanisms and opportunity for drug development. Pharmacol Ther 139:189-212. doi:10.1016/j.pharmthera. 2013.04.006

16. Perretti M, Leroy X, Bland EJ, Montero-Melendez T (2015) Resolution pharmacology: opportunities for therapeutic innovation in inflammation. Trends Pharmacol Sci 36:737-755. doi:10. 1016/j.tips.2015.07.007

17. Sonnenberg GF, Artis D (2015) Innate lymphoid cells in the initiation, regulation and resolution of inflammation. Nat Med 21: 698-708. doi:10.1038/nm.3892

18. Gilroy D, De Maeyer R (2015) New insights into the resolution of inflammation. Semin Immunol 27:161-168. doi:10.1016/j.smim. 2015.05.003

19. Tak T, Tesselaar K, Pillay J et al (2013) What's your age again? Determination of human neutrophil half-lives revisited. J Leukoc Biol 94:595-601. doi:10.1189/jlb.1112571

20. Borregaard N, Cowland JB (1997) Granules of the human neutrophilic polymorphonuclear leukocyte. Blood 89:3503-3521

21. Serhan CN (2007) Resolution phase of inflammation: novel endogenous anti-inflammatory and proresolving lipid mediators and 
pathways. Annu Rev Immunol 25:101-137. doi:10.1146/annurev. immunol.25.022106.141647

22. Jones HR, Robb CT, Perretti M, Rossi AG (2016) The role of neutrophils in inflammation resolution. Semin Immunol. doi:10. 1016/j.smim.2016.03.007

23. Kerr JF, Wyllie AH, Currie AR (1972) Apoptosis: a basic biological phenomenon with wide-ranging implications in tissue kinetics. Br J Cancer 26:239-57

24. Fridlender ZG, Albelda SM (2012) Tumor-associated neutrophils: friend or foe? Carcinogenesis 33:949-955. doi:10.1093/carcin/ bgs 123

25. Kobayashi Y (2015) Neutrophil biology: an update. EXCLI J 14: 220-227. doi: 10.17179/excli2015-102

26. Buckley CD, Ross EA, McGettrick HM et al (2006) Identification of a phenotypically and functionally distinct population of longlived neutrophils in a model of reverse endothelial migration. J Leukoc Biol 79:303-311. doi:10.1189/jlb.0905496

27. Lucas CD, Hoodless LJ, Rossi AG (2014) Swimming against the tide: drugs drive neutrophil reverse migration. Sci Transl Med 6: 225fs9. doi:10.1126/scitranslmed.3008666

28. Robertson AL, Holmes GR, Bojarczuk AN et al (2014) A zebrafish compound screen reveals modulation of neutrophil reverse migration as an anti-inflammatory mechanism. Sci Transl Med 6:225ra29. doi:10.1126/scitranslmed.3007672

29. Tauzin S, Starnes TW, Becker FB et al (2014) Redox and Src family kinase signaling control leukocyte wound attraction and neutrophil reverse migration. J Cell Biol 207:589-598. doi:10. 1083/jcb.201408090

30. Colom B, Bodkin JV, Beyrau M et al (2015) Leukotriene B4neutrophil elastase axis drives neutrophil reverse transendothelial cell migration in vivo. Immunity 42:1075-1086. doi:10.1016/j. immuni.2015.05.010

31. Ellett F, Elks PM, Robertson AL, et al. (2015) Defining the phenotype of neutrophils following reverse migration in zebrafish. $\mathrm{J}$ Leukoc Biol jlb.3MA0315-105R. doi: 10.1189/jlb.3MA0315105R

32. Powell DR, Huttenlocher A (2016) Neutrophils in the tumor microenvironment. Trends Immunol 37:41-52. doi:10.1016/j.it. 2015.11.008

33. Yousefi S, Gold JA, Andina N et al (2008) Catapult-like release of mitochondrial DNA by eosinophils contributes to antibacterial defense. Nat Med 14:949-53. doi:10.1038/nm.1855

34. Ueki S, Melo RCN, Ghiran I et al (2013) Eosinophil extracellular DNA trap cell death mediates lytic release of free secretioncompetent eosinophil granules in humans. Blood 121:20742083. doi:10.1182/blood-2012-05-432088

35. Stern M, Meagher L, Savill J, Haslett C (1992) Apoptosis in human eosinophils. Programmed cell death in the eosinophil leads to phagocytosis by macrophages and is modulated by IL-5. J Immunol 148:3543-9

36. Henderson WR, Jörg A, Klebanoff SJ (1982) Eosinophil peroxidase-mediated inactivation of leukotrienes B4, C4, and D4. J Immunol 128:2609-2613

37. Henderson WR, Jong EC, Klebanoff SJ (1980) Binding of eosinophil peroxidase to mast cell granules with retention of peroxidatic activity. J Immunol 124:1383-1388

38. Rosenberg HF, Domachowske JB (2001) Eosinophils, eosinophil ribonucleases, and their role in host defense against respiratory virus pathogens. J Leukoc Biol 70:691-698

39. Drake MG, Bivins-Smith ER, Proskocil BJ et al (2016) Human and mouse eosinophils have antiviral activity against parainfluenza virus. Am J Respir Cell Mol Biol. doi:10.1165/ rcmb.2015-0405OC

40. Felton JM, Lucas CD, Rossi AG, Dransfield I (2014) Eosinophils in the lung-modulating apoptosis and efferocytosis in airway inflammation. Front Immunol. doi:10.3389/fimmu.2014.00302
41. Falcone FH, Haas H, Gibbs BF (2000) The human basophil: a new appreciation of its role in immune responses. Blood 96:4028-4038

42. Gordon S, Plüddemann A, Martinez Estrada F (2014) Macrophage heterogeneity in tissues: phenotypic diversity and functions. Immunol Rev 262:36-55. doi:10.1111/imr.12223

43. Hussell T, Bell TJ (2014) Alveolar macrophages: plasticity in a tissue-specific context. Nat Rev Immunol 14:81-93. doi:10.1038/ nri3600

44. Martinez FO, Gordon S (2014) The M1 and M2 paradigm of macrophage activation: time for reassessment. F1000Prime Rep 6:13. doi:10.12703/P6-13

45. Murray PJ, Allen JE, Biswas SK et al (2014) Macrophage activation and polarization: nomenclature and experimental guidelines. Immunity 41:14-20. doi:10.1016/j.immuni.2014.06.008

46. Savill J (1997) Recognition and phagocytosis of cells undergoing apoptosis. Br Med Bull 53:491-508

47. Kaur M, Bell T, Salek-Ardakani S, Hussell T (2015) Macrophage adaptation in airway inflammatory resolution. Eur Respir Rev 24: 510-515. doi:10.1183/16000617.0030-2015

48. Kawkitinarong K, Linz-McGillem L, Birukov KG, Garcia JGN (2004) Differential regulation of human lung epithelial and endothelial barrier function by thrombin. Am J Respir Cell Mol Biol 31:517-527. doi: $10.1165 / \mathrm{rcmb} .2003-0432 \mathrm{OC}$

49. Crosby LM, Waters CM (2010) Epithelial repair mechanisms in the lung. Am J Physiol Lung Cell Mol Physiol 298:L715-L731. doi:10.1152/ajplung.00361.2009

50. Borish L, Joseph BZ (1992) Inflammation and the allergic response. Med Clin N Am 76:765-787

51. Amin K (2012) The role of mast cells in allergic inflammation. Respir Med 106:9-14. doi:10.1016/j.rmed.2011.09.007

52. Culley FJ (2009) Natural killer cells in infection and inflammation of the lung. Immunology 128:151-163. doi:10.1111/j.1365-2567. 2009.03167.x

53. Condon TV, Sawyer RT, Fenton MJ, Riches DWH (2011) Lung dendritic cells at the innate-adaptive immune interface. J Leukoc Biol 90:883-895. doi:10.1189/jlb.0311134

54. Fox S, Leitch AE, Duffin R et al (2010) Neutrophil apoptosis: relevance to the innate immune response and inflammatory disease. J Innate Immun 2:216-227. doi:10.1159/000284367

55. Thornberry NA, Lazebnik Y (1998) Caspases: enemies within. Science 281:1312-1316

56. Earnshaw WC, Martins LM, Kaufmann SH (1999) Mammalian caspases: structure, activation, substrates, and functions during apoptosis. Annu Rev Biochem 68:383-424. doi:10.1146/ annurev.biochem.68.1.383

57. Maianski NA, Roos D, Kuijpers TW (2003) Tumor necrosis factor alpha induces a caspase-independent death pathway in human neutrophils. Blood 101:1987-1995. doi:10.1182/blood-2002-020522

58. Li H, Zhu H, Xu CJ, Yuan J (1998) Cleavage of BID by caspase 8 mediates the mitochondrial damage in the Fas pathway of apoptosis. Cell 94:491-501

59. Schug ZT, Gonzalvez F, Houtkooper RH et al (2011) BID is cleaved by caspase- 8 within a native complex on the mitochondrial membrane. Cell Death Differ 18:538-548. doi:10.1038/cdd. 2010.135

60. Arandjelovic S, Ravichandran KS (2015) Phagocytosis of apoptotic cells in homeostasis. Nat Immunol 16:907-917. doi:10.1038/ ni. 3253

61. Truman LA, Ford CA, Pasikowska M et al (2008) CX3CL1/ fractalkine is released from apoptotic lymphocytes to stimulate macrophage chemotaxis. Blood 112:5026-5036. doi:10.1182/ blood-2008-06-162404

62. Lauber K, Bohn E, Kröber SM et al (2003) Apoptotic cells induce migration of phagocytes via caspase-3-mediated release of a lipid attraction signal. Cell 113:717-730 
63. Gude DR, Alvarez SE, Paugh SW et al (2008) Apoptosis induces expression of sphingosine kinase 1 to release sphingosine-1phosphate as a "come-and-get-me" signal. FASEB J 22:26292638. doi:10.1096/fj.08-107169

64. Elliott MR, Chekeni FB, Trampont PC et al (2009) Nucleotides released by apoptotic cells act as a find-me signal to promote phagocytic clearance. Nature 461:282-286. doi:10.1038/ nature 08296

65. Gardai SJ, Bratton DL, Ogden CA, Henson PM (2006) Recognition ligands on apoptotic cells: a perspective. J Leukoc Biol 79:896-903. doi:10.1189/jlb.1005550

66. Fadok VA, Voelker DR, Campbell PA et al (1992) Exposure of phosphatidylserine on the surface of apoptotic lymphocytes triggers specific recognition and removal by macrophages. J Immunol 148:2207-2216

67. Fadok VA, Bratton DL, Rose DM et al (2000) A receptor for phosphatidylserine-specific clearance of apoptotic cells. Nature 405:85-90. doi:10.1038/35011084

68. Hochreiter-Hufford A, Ravichandran KS (2013) Clearing the dead: apoptotic cell sensing, recognition, engulfment, and digestion. Cold Spring Harb Perspe ct Biol 5:a008748. doi:10.1101/ cshperspect.a008748

69. Serhan CN, Chiang N, Dalli J, Levy BD (2014) Lipid mediators in the resolution of inflammation. Cold Spring Harb Perspect Biol a016311. doi: 10.1101/cshperspect.a016311

70. Cavassani KA, Ishii M, Wen $\mathrm{H}$ et al (2008) TLR3 is an endogenous sensor of tissue necrosis during acute inflammatory events. $\mathrm{J}$ Exp Med 205:2609-2621. doi:10.1084/jem.20081370

71. Zitvogel L, Kepp O, Kroemer G (2010) Decoding cell death signals in inflammation and immunity. Cell 140:798-804. doi:10. 1016/j.cell.2010.02.015

72. Kono H, Rock KL (2008) How dying cells alert the immune system to danger. Nat Rev Immunol 8:279-289. doi:10.1038/ nri2215

73. Brinkmann V, Reichard U, Goosmann C et al (2004) Neutrophil extracellular traps kill bacteria. Science 303:1532-5

74. Yousefi S, Mihalache C, Kozlowski E et al (2009) Viable neutrophils release mitochondrial DNA to form neutrophil extracellular traps. Cell Death Differ 16:1438-44. doi:10.1038/ cdd.2009.96

75. Pilsczek FH, Salina D, Poon KKH et al (2010) A novel mechanism of rapid nuclear neutrophil extracellular trap formation in response to Staphylococcus aureus. J Immunol 185:7413-7425. doi:10.4049/jimmunol.1000675

76. Fuchs TA, Abed U, Goosmann C et al (2007) Novel cell death program leads to neutrophil extracellular traps. J Cell Biol 176: $231-41$

77. Urban CF, Ermert D, Schmid M et al (2009) Neutrophil extracellular traps contain calprotectin, a cytosolic protein complex involved in host defense against Candida albicans. PLoS Pathog 5:e1000639. doi:10.1371/journal.ppat.1000639

78. Neeli I, Radic M (2012) Knotting the NETs: analyzing histone modifications in neutrophil extracellular traps. Arthritis Res Ther 14:115. doi:10.1186/ar3773

79. Neeli I, Dwivedi N, Khan S, Radic M (2009) Regulation of extracellular chromatin release from neutrophils. J Innate Immun 1: 194-201. doi:10.1159/000206974

80. Gray RD, Lucas CD, Mackellar A et al (2013) Activation of conventional protein kinase $\mathrm{C}(\mathrm{PKC})$ is critical in the generation of human neutrophil extracellular traps. J Inflamm (Lond) 10:12. doi: 10.1186/1476-9255-10-12

81. Saitoh T, Komano J, Saitoh Y et al (2012) Neutrophil extracellular traps mediate a host defense response to human immunodeficiency virus-1. Cell Host Microbe 12:109-116. doi:10.1016/j.chom. 2012.05.015
82. Urban CF, Reichard U, Brinkmann V, Zychlinsky A (2006) Neutrophil extracellular traps capture and kill Candida albicans yeast and hyphal forms. Cell Microbiol 8:668-76

83. Abi Abdallah DS, Lin C, Ball CJ et al (2012) Toxoplasma gondii triggers release of human and mouse neutrophil extracellular traps. Infect Immun 80:768-777. doi:10.1128/IAI.05730-11

84. Wartha F, Beiter K, Albiger B et al (2007) Capsule and Dalanylated lipoteichoic acids protect Streptococcus pneumoniae against neutrophil extracellular traps. Cell Microbiol 9:11621171. doi:10.1111/j.1462-5822.2006.00857.x

85. Buchanan JT, Simpson AJ, Aziz RK et al (2006) DNase expression allows the pathogen group A Streptococcus to escape killing in neutrophil extracellular traps. Curr Biol 16:396-400. doi:10. 1016/j.cub.2005.12.039

86. Steinberg BE, Grinstein S (2007) Unconventional roles of the NADPH oxidase: signaling, ion homeostasis, and cell death. Sci STKE 2007:pe11. doi:10.1126/stke.3792007pe11

87. Wartha F, Henriques-Normark B (2008) ETosis: a novel cell death pathway. Sci Signal 1:pe25. doi:10.1126/stke.121pe25

88. Robb CT, Dyrynda EA, Gray RD et al (2014) Invertebrate extracellular phagocyte traps show that chromatin is an ancient defence weapon. Nat Commun 5:4627. doi:10.1038/ncomms5627

89. Kasama T, Miwa Y, Isozaki T et al (2005) Neutrophil-derived cytokines: potential therapeutic targets in inflammation. Curr Drug Targets Inflamm Allergy 4:273-279

90. Zawrotniak M, Rapala-Kozik M (2013) Neutrophil extracellular traps (NETs) - formation and implications. Acta Biochim Pol 60: 277-284

91. Bosmann M, Grailer JJ, Ruemmler R et al (2013) Extracellular histones are essential effectors of C5aR- and C5L2-mediated tissue damage and inflammation in acute lung injury. FASEB J 27: 5010-5021. doi:10.1096/fj.13-236380

92. Caudrillier A, Kessenbrock K, Gilliss BM et al (2012) Platelets induce neutrophil extracellular traps in transfusion-related acute lung injury. J Clin Invest 122:2661-2671. doi:10.1172/JCI61303

93. Narasaraju T, Yang E, Samy RP et al (2011) Excessive neutrophils and neutrophil extracellular traps contribute to acute lung injury of influenza pneumonitis. Am J Pathol 179:199-210. doi:10.1016/j. ajpath.2011.03.013

94. Manzenreiter R, Kienberger F, Marcos V et al (2012) Ultrastructural characterization of cystic fibrosis sputum using atomic force and scanning electron microscopy. J Cyst Fibros 11:84-92. doi:10.1016/j.jcf.2011.09.008

95. Dwyer M, Shan Q, Ortona SD et al (2014) Cystic fibrosis sputum DNA has NETosis characteristics and neutrophil extracellular trap release is regulated by macrophage migration-inhibitory factor. $\mathrm{J}$ Innate Immun 6:765-779. doi:10.1159/000363242

96. Fuxman Bass JI, Russo DM, Gabelloni ML et al (2010) Extracellular DNA: a major proinflammatory component of Pseudomonas aeruginosa biofilms. J Immunol 184:6386-6395. doi:10.4049/jimmunol.0901640

97. Young RL, Malcolm KC, Kret JE et al (2011) Neutrophil extracellular trap (NET)-mediated killing of Pseudomonas aeruginosa: evidence of acquired resistance within the $\mathrm{CF}$ airway, independent of CFTR. PLoS One 6:e23637. doi:10.1371/journal.pone. 0023637

98. Dworski R, Simon H-U, Hoskins A, Yousefi S (2011) Eosinophil and neutrophil extracellular DNA traps in human allergic asthmatic airways. J Allergy Clin Immunol 127:1260-1266. doi:10.1016/ j.jaci.2010.12.1103

99. Grabcanovic-Musija F, Obermayer A, Stoiber W et al (2015) Neutrophil extracellular trap (NET) formation characterises stable and exacerbated COPD and correlates with airflow limitation. Respir Res. doi:10.1186/s12931-015-0221-7

100. Pedersen F, Marwitz S, Holz O et al (2015) Neutrophil extracellular trap formation and extracellular DNA in sputum of stable 
COPD patients. Respir Med 109:1360-1362. doi:10.1016/j.rmed. 2015.08.008

101. Ramos-Kichik V, Mondragón-Flores R, Mondragón-Castelán M et al (2009) Neutrophil extracellular traps are induced by Mycobacterium tuberculosis. Tuberculosis (Edinb) 89:29-37. doi:10.1016/j.tube.2008.09.009

102. Cheng OZ, Palaniyar N (2013) NET balancing: a problem in inflammatory lung diseases. Front Immunol. doi:10.3389/fimmu. 2013.00001

103. Röhm M, Grimm MJ, Auria ACD et al (2014) NADPH oxidase promotes neutrophil extracellular trap formation in pulmonary aspergillosis. Infect Immun 82:1766-1777. doi:10.1128/IAI.0009614

104. Coxon A, Rieu P, Barkalow FJ et al (1996) A novel role for the beta 2 integrin $\mathrm{CD} 11 \mathrm{~b} / \mathrm{CD} 18$ in neutrophil apoptosis: a homeostatic mechanism in inflammation. Immunity 5:653-666

105. Romani L, Fallarino F, De Luca A et al (2008) Defective tryptophan catabolism underlies inflammation in mouse chronic granulomatous disease. Nature 451:211-215. doi:10.1038/nature06471

106. Ryter SW, Choi AMK (2015) Autophagy in lung disease pathogenesis and therapeutics. Redox Biol 4:215-225. doi:10.1016/j. redox.2014.12.010

107. Ponpuak M, Davis AS, Roberts EA et al (2010) Delivery of cytosolic components by autophagic adaptor protein p62 endows autophagosomes with unique antimicrobial properties. Immunity 32:329-341. doi:10.1016/j.immuni.2010.02.009

108. Zhang R, Chi X, Wang S et al (2014) The regulation of autophagy by influenza A virus, the regulation of autophagy by influenza A virus. BioMed Res Int 2014:498083. doi:10.1155/2014/498083

109. Lam HC, Cloonan SM, Bhashyam AR et al (2013) Histone deacetylase 6-mediated selective autophagy regulates COPDassociated cilia dysfunction. J Clin Invest 123:5212-5230. doi: 10.1172/JCI69636

110. Qing DY, Conegliano D, Shashaty MGS et al (2014) Red blood cells induce necroptosis of lung endothelial cells and increase susceptibility to lung inflammation. Am J Respir Crit Care Med 190: 1243-1254. doi:10.1164/rccm.201406-1095OC

111. Kitur K, Parker D, Nieto P et al (2015) Toxin-induced necroptosis is a major mechanism of Staphylococcus aureus lung damage. PLoS Pathog 11:e1004820. doi:10.1371/journal.ppat.1004820

112. Pouwels SD, Zijlstra GJ, van der Toorn M, et al. (2015) Cigarette smoke-induced necroptosis and DAMP release trigger neutrophilic airway inflammation in mice. Am J Physiol Lung Cell Mol Physiol ajplung.00174.2015. doi: 10.1152/ajplung.00174.2015

113. Parnaik R, Raff MC, Scholes J (2000) Differences between the clearance of apoptotic cells by professional and non-professional phagocytes. Curr Biol 10:857-860

114. Wood W, Turmaine M, Weber R et al (2000) Mesenchymal cells engulf and clear apoptotic footplate cells in macrophageless PU.1 null mouse embryos. Development 127:5245-5252

115. Blume KE, Soeroes S, Keppeler H et al (2012) Cleavage of annexin A1 by ADAM10 during secondary necrosis generates a monocytic "find-me" signal. J Immunol 188:135-145. doi:10. 4049/jimmunol.1004073

116. Arur S, Uche UE, Rezaul K et al (2003) Annexin I is an endogenous ligand that mediates apoptotic cell engulfment. Dev Cell 4: 587-598

117. Bournazou I, Pound JD, Duffin R et al (2009) Apoptotic human cells inhibit migration of granulocytes via release of lactoferrin. $\mathrm{J}$ Clin Invest 119:20-32. doi:10.1172/JCI36226

118. Bournazou I, Mackenzie KJ, Duffin R et al (2010) Inhibition of eosinophil migration by lactoferrin. Immunol Cell Biol 88:220 223. doi:10.1038/icb.2009.86

119. Park D, Tosello-Trampont A-C, Elliott MR et al (2007) BAI1 is an engulfment receptor for apoptotic cells upstream of the ELMO/
Dock180/Rac module. Nature 450:430-434. doi:10.1038/ nature 06329

120. Park S-Y, Jung M-Y, Kim H-J et al (2008) Rapid cell corpse clearance by stabilin-2, a membrane phosphatidylserine receptor Cell Death Differ 15:192-201. doi:10.1038/si.cdd.4402242

121. Kobayashi N, Karisola P, Peña-Cruz V et al (2007) TIM-1 and TIM-4 glycoproteins bind phosphatidylserine and mediate uptake of apoptotic cells. Immunity 27:927-940. doi:10.1016/j.immuni. 2007.11.011

122. Nakayama M, Akiba H, Takeda K et al (2009) Tim-3 mediates phagocytosis of apoptotic cells and cross-presentation. Blood 113: 3821-3830. doi:10.1182/blood-2008-10-185884

123. Lee S-J, So I-S, Park S-Y, Kim I-S (2008) Thymosin beta4 is involved in stabilin-2-mediated apoptotic cell engulfment. FEBS Lett 582:2161-2166. doi:10.1016/j.febslet.2008.03.058

124. Park S-Y, Kang K-B, Thapa N et al (2008) Requirement of adaptor protein GULP during stabilin-2-mediated cell corpse engulfment. J Biol Chem 283:10593-10600. doi:10.1074/jbc.M709105200

125. Toda S, Hanayama R, Nagata S (2012) Two-step engulfment of apoptotic cells. Mol Cell Biol 32:118-125. doi:10.1128/MCB. 05993-11

126. Hanayama R, Tanaka M, Miwa K et al (2002) Identification of a factor that links apoptotic cells to phagocytes. Nature 417:182187. doi:10.1038/417182a

127. Anderson HA, Maylock CA, Williams JA et al (2003) Serumderived protein $\mathrm{S}$ binds to phosphatidylserine and stimulates the phagocytosis of apoptotic cells. Nat Immunol 4:87-91. doi:10. 1038/ni871

128. Ishimoto Y, Ohashi K, Mizuno K, Nakano T (2000) Promotion of the uptake of PS liposomes and apoptotic cells by a product of growth arrest-specific gene, gas6. J Biochem 127:411-417

129. Gardai SJ, McPhillips KA, Frasch SC et al (2005) Cell-surface calreticulin initiates clearance of viable or apoptotic cells through trans-activation of LRP on the phagocyte. Cell 123:321-334. doi: 10.1016/j.cell.2005.08.032

130. Obeid M, Tesniere A, Ghiringhelli $\mathrm{F}$ et al (2007) Calreticulin exposure dictates the immunogenicity of cancer cell death. Nat Med 13:54-61. doi:10.1038/nm1523

131. Liu Y, Cousin JM, Hughes J et al (1999) Glucocorticoids promote nonphlogistic phagocytosis of apoptotic leukocytes. J Immunol 162:3639-3646

132. Giles KM, Ross K, Rossi AG et al (2001) Glucocorticoid augmentation of macrophage capacity for phagocytosis of apoptotic cells is associated with reduced p130Cas expression, loss of paxillin/ pyk2 phosphorylation, and high levels of active Rac. J Immunol 167:976-986

133. McColl A, Bournazos S, Franz S et al (2009) Glucocorticoids induce protein S-dependent phagocytosis of apoptotic neutrophils by human macrophages. J Immunol 183:2167-2175. doi:10.4049/ jimmunol.0803503

134. Scott RS, McMahon EJ, Pop SM et al (2001) Phagocytosis and clearance of apoptotic cells is mediated by MER. Nature 411:207211. doi: $10.1038 / 35075603$

135. Choi J-Y, Park H-J, Lee Y-J et al (2013) Upregulation of Mer receptor tyrosine kinase signaling attenuated lipopolysaccharideinduced lung inflammation. J Pharmacol Exp Ther 344:447-458. doi:10.1124/jpet.112.199778

136. Thorp E, Vaisar T, Subramanian M et al (2011) Shedding of the Mer tyrosine kinase receptor is mediated by ADAM17 protein through a pathway involving reactive oxygen species, protein kinase $\mathrm{C} \delta$, and $\mathrm{p} 38$ mitogen-activated protein kinase (MAPK). J Biol Chem 286:33335-33344. doi:10.1074/jbc.M111.263020

137. Lee Y-J, Lee S-H, Youn Y-S et al (2012) Preventing cleavage of Mer promotes efferocytosis and suppresses acute lung injury in bleomycin treated mice. Toxicol Appl Pharmacol 263:61-72. doi: 10.1016/j.taap.2012.05.024 
138. Marwick JA, Dorward DA, Lucas CD et al (2013) Oxygen levels determine the ability of glucocorticoids to influence neutrophil survival in inflammatory environments. J Leukoc Biol 94:12851292. doi:10.1189/jlb.0912462

139. Perretti M, Acquisto FD (2009) Annexin A1 and glucocorticoids as effectors of the resolution of inflammation. Nat Rev Immunol 9: 62-70. doi:10.1038/nri2470

140. Perretti M, Chiang N, La M et al (2002) Endogenous lipid- and peptide-derived anti-inflammatory pathways generated with glucocorticoid and aspirin treatment activate the lipoxin A4 receptor. Nat Med 8:1296-1302. doi:10.1038/nm786

141. Perretti M, Christian H, Wheller SK et al (2000) Annexin I is stored within gelatinase granules of human neutrophil and mobilized on the cell surface upon adhesion but not phagocytosis. Cell Biol Int 24:163-174. doi:10.1006/cbir.1999.0468

142. Maderna P, Yona S, Perretti M, Godson C (2005) Modulation of phagocytosis of apoptotic neutrophils by supernatant from dexamethasone-treated macrophages and annexin-derived peptide Ac2-26. J Immunol 174:3727-3733. doi:10.4049/jimmunol.174. 6.3727

143. Scannell M, Flanagan MB, deStefani A et al (2007) Annexin-1 and peptide derivatives are released by apoptotic cells and stimulate phagocytosis of apoptotic neutrophils by macrophages. J Immunol 178:4595-4605

144. Goulding NJ, Godolphin JL, Sharland PR et al (1990) Antiinflammatory lipocortin 1 production by peripheral blood leucocytes in response to hydrocortisone. Lancet 335:1416-1418

145. Mulla A, LeRoux C, Solito E, Buckingham JC (2005) Correlation between the antiinflammatory protein annexin 1 (lipocortin 1) and serum cortisol in subjects with normal and dysregulated adrenal function. J Clin Endocrinol Metab 90:557-562. doi:10.1210/jc. 2004-1230

146. Vago JP, Nogueira CRC, Tavares LP et al (2012) Annexin A1 modulates natural and glucocorticoid-induced resolution of inflammation by enhancing neutrophil apoptosis. J Leukoc Biol 92:249-258. doi:10.1189/jlb.0112008

147. Morimoto K, Janssen WJ, Fessler MB et al (2006) Lovastatin enhances clearance of apoptotic cells (efferocytosis) with implications for chronic obstructive pulmonary disease. J Immunol 176: 7657-7665

148. Yun JH, Henson PM, Tuder RM (2008) Phagocytic clearance of apoptotic cells: role in lung disease. Expert Rev Respir Med 2: 753-765. doi:10.1586/17476348.2.6.753

149. Grabiec AM, Hussell T (2016) The role of airway macrophages in apoptotic cell clearance following acute and chronic lung inflammation. Semin Immunopathol. doi:10.1007/s00281-016-0555-3

150. Dockrell DH, Marriott HM, Prince LR et al (2003) Alveolar macrophage apoptosis contributes to pneumococcal clearance in a resolving model of pulmonary infection. J Immunol 171:5380-5388

151. Aberdein JD, Cole J, Bewley MA et al (2013) Alveolar macrophages in pulmonary host defence the unrecognized role of apoptosis as a mechanism of intracellular bacterial killing. Clin Exp Immunol 174:193-202. doi:10.1111/cei.12170

152. Curtis JL, Todt JC, Hu B et al (2009) Tyro3 receptor tyrosine kinases in the heterogeneity of apoptotic cell uptake. Front Biosci (Landmark Ed) 14:2631-2646

153. Janssen WJ, McPhillips KA, Dickinson MG et al (2008) Surfactant proteins A and D suppress alveolar macrophage phagocytosis via interaction with SIRP alpha. Am J Respir Crit Care Med 178:158-167. doi:10.1164/rccm.200711-1661OC

154. McCubbrey AL, Curtis JL (2013) Efferocytosis and lung disease. Chest 143:1750-1757. doi:10.1378/chest.12-2413

155. Xiong Z, Leme AS, Ray P et al (2011) CX3CR1+ lung mononuclear phagocytes spatially confined to the interstitium produce TNF- $\alpha$ and IL- 6 and promote cigarette smoke-induced emphysema. J Immunol 186:3206-3214. doi:10.4049/jimmunol.1003221
156. Desch AN, Randolph GJ, Murphy K et al (2011) CD103+ pulmonary dendritic cells preferentially acquire and present apoptotic cell-associated antigen. J Exp Med 208:1789-1797. doi:10.1084/ jem.20110538

157. Walsh GM, Sexton DW, Blaylock MG, Convery CM (1999) Resting and cytokine-stimulated human small airway epithelial cells recognize and engulf apoptotic eosinophils. Blood 94: $2827-2835$

158. Sexton DW, Blaylock MG, Walsh GM (2001) Human alveolar epithelial cells engulf apoptotic eosinophils by means of integrin- and phosphatidylserine receptor-dependent mechanisms: a process upregulated by dexamethasone. J Allergy Clin Immunol 108:962-969. doi:10.1067/mai.2001.119414

159. Juncadella IJ, Kadl A, Sharma AK et al (2013) Apoptotic cell clearance by bronchial epithelial cells critically influences airway inflammation. Nature 493:547-551. doi:10.1038/nature11714

160. Samuelsson B, Dahlén SE, Lindgren JA et al (1987) Leukotrienes and lipoxins: structures, biosynthesis, and biological effects. Science 237:1171-1176

161. Levy BD, Serhan CN (2014) Resolution of acute inflammation in the lung. Annu Rev Physiol 76:467-492. doi:10.1146/annurevphysiol-021113-170408

162. Serhan CN, Chiang N, Van Dyke TE (2008) Resolving inflammation: dual anti-inflammatory and pro-resolution lipid mediators. Nat Rev Immunol 8:349-361. doi:10.1038/nri2294

163. Serhan CN (2014) Pro-resolving lipid mediators are leads for resolution physiology. Nature 510:92-101. doi:10.1038/nature13479

164. Gilroy DW, Colville-Nash PR, Willis D et al (1999) Inducible cyclooxygenase may have anti-inflammatory properties. Nat Med 5:698-701. doi:10.1038/9550

165. Fukunaga K, Kohli P, Bonnans C et al (2005) Cyclooxygenase 2 plays a pivotal role in the resolution of acute lung injury. $\mathrm{J}$ Immunol 174:5033-5039

166. Schwab JM, Chiang N, Arita M, Serhan CN (2007) Resolvin E1 and protectin D1 activate inflammation-resolution programmes. Nature 447:869-874. doi:10.1038/nature05877

167. Ye RD, Boulay F, Wang JM et al (2009) International Union of Basic and Clinical Pharmacology. LXXIII. Nomenclature for the formyl peptide receptor (FPR) family. Pharmacol Rev 61:119 161. doi:10.1124/pr.109.001578

168. Serhan CN, Hamberg M, Samuelsson B (1984) Lipoxins: novel series of biologically active compounds formed from arachidonic acid in human leukocytes. Proc Natl Acad Sci U S A 81:53355339

169. Serhan CN, Sheppard KA (1990) Lipoxin formation during human neutrophil-platelet interactions. Evidence for the transformation of leukotriene A4 by platelet 12-lipoxygenase in vitro. J Clin Invest 85:772-780. doi:10.1172/JCI114503

170. Levy BD, Romano M, Chapman HA et al (1993) Human alveolar macrophages have 15-lipoxygenase and generate 15(S)-hydroxy5,8,11-cis-13-trans-eicosatetraenoic acid and lipoxins. J Clin Invest 92:1572-1579. doi:10.1172/JCI116738

171. Chiang N, Serhan CN, Dahlén S-E et al (2006) The lipoxin receptor ALX: potent ligand-specific and stereoselective actions in vivo. Pharmacol Rev 58:463-487. doi:10.1124/pr.58.3.4

172. Krishnamoorthy S, Recchiuti A, Chiang N et al (2012) Resolvin D1 receptor stereoselectivity and regulation of inflammation and proresolving microRNAs. Am J Pathol 180:2018-2027. doi:10. 1016/j.ajpath.2012.01.028

173. Krishnamoorthy S, Recchiuti A, Chiang N et al (2010) Resolvin D1 binds human phagocytes with evidence for proresolving receptors. Proc Natl Acad Sci U S A 107:1660-1665. doi:10.1073/ pnas.0907342107

174. Norling LV, Dalli J, Flower RJ et al (2012) Resolvin D1 limits polymorphonuclear leukocyte recruitment to inflammatory loci: 
receptor-dependent actions. Arterioscler Thromb Vasc Biol 32: 1970-1978. doi:10.1161/ATVBAHA.112.249508

175. Arita M, Ohira T, Sun Y-P et al (2007) Resolvin E1 selectively interacts with leukotriene B4 receptor BLT1 and ChemR23 to regulate inflammation. J Immunol 178:3912-3917

176. Serhan CN, Gotlinger K, Hong S et al (2006) Anti-inflammatory actions of neuroprotectin D1/protectin D1 and its natural stereoisomers: assignments of dihydroxy-containing docosatrienes. J Immunol 176:1848-1859

177. Marcheselli VL, Hong S, Lukiw WJ et al (2003) Novel docosanoids inhibit brain ischemia-reperfusion-mediated leukocyte infiltration and pro-inflammatory gene expression. J Biol Chem 278:43807-43817. doi:10.1074/jbc.M305841200

178. Serhan CN, Yang R, Martinod K et al (2009) Maresins: novel macrophage mediators with potent antiinflammatory and proresolving actions. J Exp Med 206:15-23. doi:10.1084/jem. 20081880

179. Dalli J, Zhu M, Vlasenko NA et al (2013) The novel 13S,14Sepoxy-maresin is converted by human macrophages to maresin 1 (MaR1), inhibits leukotriene A4 hydrolase (LTA4H), and shifts macrophage phenotype. FASEB J 27:2573-2583. doi:10.1096/fj. 13-227728

180. Serhan CN, Dalli J, Karamnov S et al (2012) Macrophage proresolving mediator maresin 1 stimulates tissue regeneration and controls pain. FASEB J 26:1755-1765. doi:10.1096/fj.11201442

181. Levy BD, Bonnans C, Silverman ES et al (2005) Diminished lipoxin biosynthesis in severe asthma. Am J Respir Crit Care Med 172:824-830. doi:10.1164/rccm.200410-1413OC

182. Karp CL, Flick LM, Park KW et al (2004) Defective lipoxinmediated anti-inflammatory activity in the cystic fibrosis airway. Nat Immunol 5:388-392. doi:10.1038/ni1056

183. Sanak M, Levy BD, Clish CB et al (2000) Aspirin-tolerant asthmatics generate more lipoxins than aspirin-intolerant asthmatics. Eur Respir J 16:44-49

184. Kowal-Bielecka O, Kowal K, Distler O et al (2005) Cyclooxygenaseand lipoxygenase-derived eicosanoids in bronchoalveolar lavage fluid from patients with scleroderma lung disease: an imbalance between proinflammatory and antiinflammatory lipid mediators. Arthritis Rheum 52:3783-3791. doi:10. 1002/art.21432

185. Levy BD, Vachier I, Serhan CN (2012) Resolution of inflammation in asthma. Clin Chest Med 33:559-570. doi:10.1016/j.ccm. 2012.06.006

186. Freedman SD, Blanco PG, Zaman MM et al (2004) Association of cystic fibrosis with abnormalities in fatty acid metabolism. N Engl J Med 350:560-569. doi:10.1056/NEJMoa021218

187. Haworth O, Cernadas M, Levy BD (2011) NK cells are effectors for resolvin E1 in the timely resolution of allergic airway inflammation. J Immunol 186:6129-6135. doi:10.4049/jimmunol. 1004007

188. Rogerio AP, Haworth O, Croze R et al (2012) Resolvin D1 and aspirin-triggered resolvin D1 promote resolution of allergic airways responses. J Immunol 189:1983-1991. doi:10.4049/ jimmunol.1101665

189. Haworth O, Cernadas M, Yang R et al (2008) Resolvin E1 regulates interleukin 23, interferon-gamma and lipoxin A4 to promote the resolution of allergic airway inflammation. Nat Immunol 9: 873-879. doi:10.1038/ni.1627

190. Winkler J, Orr S, Dalli J et al (2015) Resolvin D4 potent antiiinflammatory proresolving actions confirmed via total synthesis. FASEB J 29:285.10

191. Winkler JW, Orr SK, Dalli J et al (2016) Resolvin D4 stereoassignment and its novel actions in host protection and bacterial clearance. Sci Rep 6:18972. doi:10.1038/srep18972
192. Levy BD, Kohli P, Gotlinger K et al (2007) Protectin D1 is generated in asthma and dampens airway inflammation and hyperresponsiveness. J Immunol 178:496-502

193. Freire MO (2000) Van Dyke TE (2013) Natural resolution of inflammation. Periodontol 63:149-164. doi:10.1111/prd.12034

194. Basil MC, Levy BD (2016) Specialized pro-resolving mediators: endogenous regulators of infection and inflammation. Nat Rev Immunol 16:51-67. doi:10.1038/nri.2015.4

195. Kolaczkowska E, Kubes P (2013) Neutrophil recruitment and function in health and inflammation. Nat Rev Immunol 13:159 175. doi:10.1038/nri3399

196. José R, Williams A, Sulikowski M et al (2015) Regulation of neutrophilic inflammation in lung injury induced by communityacquired pneumonia. Lancet 385(Suppl 1):S52. doi:10.1016/ S0140-6736(15)60367-1

197. Akinosoglou K, Alexopoulos D (2014) Use of antiplatelet agents in sepsis: a glimpse into the future. Thromb Res 133:131-138. doi: 10.1016/j.thromres.2013.07.002

198. de Boer JD, Kager LM, Roelofs JJTH et al (2014) Overexpression of activated protein $\mathrm{C}$ hampers bacterial dissemination during pneumococcal pneumonia. BMC Infect Dis 14:559. doi:10.1186/ s12879-014-0559-3

199. Arnold FW, Bordon J, Fernandez-Botran R et al (2015) Macrolide use and neutrophil function/cytokine levels in hospitalized patients with community-acquired pneumonia: a pilot study. Lung. doi:10. 1007/s00408-015-9822-7

200. Mandal P, Chalmers JD, Graham C et al (2014) Atorvastatin as a stable treatment in bronchiectasis: a randomised controlled trial. Lancet Respir Med 2:455-463. doi:10.1016/S2213-2600(14) 70050-5

201. Troeman DPR, Postma DF, van Werkhoven CH, Oosterheert JJ (2013) The immunomodulatory effects of statins in communityacquired pneumonia: a systematic review. J Infect 67:93-101. doi: 10.1016/j.jinf.2013.04.015

202. Moret I, Lorenzo MJ, Sarria B et al (2011) Increased lung neutrophil apoptosis and inflammation resolution in nonresponding pneumonia. Eur Respir J 38:1158-1164. doi:10.1183/09031936. 00190410

203. Rossi AG, Sawatzky DA, Walker A et al (2006) Cyclin-dependent kinase inhibitors enhance the resolution of inflammation by promoting inflammatory cell apoptosis. Nat Med 12:1056-1064. doi: $10.1038 / \mathrm{nm} 1468$

204. Hoogendijk AJ, Roelofs JJTH, Duitman J et al (2012) Rroscovitine reduces lung inflammation induced by lipoteichoic acid and Streptococcus pneumoniae. Mol Med 18:1086-1095. doi:10.2119/molmed.2012.00033

205. Lucas CD, Dorward DA, Tait MA et al (2014) Downregulation of Mcl-1 has anti-inflammatory pro-resolution effects and enhances bacterial clearance from the lung. Mucosal Immunol 7:857-868. doi:10.1038/mi.2013.102

206. Castro CY (2006) ARDS and diffuse alveolar damage: a pathologist's perspective. Semin Thorac Cardiovasc Surg 18:13-19. doi: 10.1053/j.semtcvs.2006.02.001

207. Piantadosi CA, Schwartz DA (2004) The acute respiratory distress syndrome. Ann Intern Med 141:460-470

208. Estenssoro E, Dubin A, Laffaire E et al (2002) Incidence, clinical course, and outcome in 217 patients with acute respiratory distress syndrome. Crit Care Med 30:2450-2456. doi:10.1097/01.CCM. 0000034692.46267 .02

209. Steinberg KP, Milberg JA, Martin TR et al (1994) Evolution of bronchoalveolar cell populations in the adult respiratory distress syndrome. Am J Respir Crit Care Med 150:113-122. doi:10.1164/ ajrccm.150.1.8025736

210. Headley AS, Tolley E, Meduri GU (1997) Infections and the inflammatory response in acute respiratory distress syndrome. Chest 111:1306-1321 
211. Steinberg KP, Hudson LD, Goodman RB et al (2006) Efficacy and safety of corticosteroids for persistent acute respiratory distress syndrome. N Engl J Med 354:1671-1684. doi:10.1056/ NEJMoa051693

212. Meduri GU, Marik PE, Chrousos GP et al (2008) Steroid treatment in ARDS: a critical appraisal of the ARDS network trial and the recent literature. Intensive Care Med 34:61-69. doi:10.1007/ s00134-007-0933-3

213. Peter JV, John P, Graham PL et al (2008) Corticosteroids in the prevention and treatment of acute respiratory distress syndrome (ARDS) in adults: meta-analysis. BMJ 336:1006-1009. doi:10. 1136/bmj.39537.939039.BE

214. Tang BMP, Craig JC, Eslick GD et al (2009) Use of corticosteroids in acute lung injury and acute respiratory distress syndrome: a systematic review and meta-analysis. Crit Care Med 37:1594 1603. doi:10.1097/CCM.0b013e31819fb507

215. Kawashima M, Yatsunami J, Fukuno Y et al (2014) Inhibitory effects of 14-membered ring macrolide antibiotics on bleomycininduced acute lung injury. Lung 180:73-89. doi:10.1007/ PL00021246

216. Leiva M, Ruiz-Bravo A, Jimenez-Valera M (2008) Effects of telithromycin in in vitro and in vivo models of lipopolysaccharideinduced airway inflammation. Chest 134:20-29. doi:10.1378/chest. 07-3056

217. Noto MJ, Wheeler AP (2012) Macrolides for acute lung injury. Chest 141:1131-1132. doi:10.1378/chest.11-3245

218. Walkey AJ, Wiener RS (2012) Macrolide antibiotics and survival in patients with acute lung injury. Chest 141:1153-1159. doi:10. 1378/chest.11-1908

219. Bernard GR, Wheeler AP, Russell JA et al (1997) The effects of ibuprofen on the physiology and survival of patients with sepsis. The Ibuprofen in Sepsis Study Group. N Engl J Med 336:912918. doi:10.1056/NEJM199703273361303

220. Heijerman H (2005) Infection and inflammation in cystic fibrosis: a short review. J Cyst Fibros 4(Suppl 2):3-5. doi:10.1016/j.jcf. 2005.05.005

221. Mott LS, Park J, Murray CP et al (2012) Progression of early structural lung disease in young children with cystic fibrosis assessed using CT. Thorax 67:509-516. doi:10.1136/thoraxjnl2011-200912

222. Lipuma JJ (2010) The changing microbial epidemiology in cystic fibrosis. Clin Microbiol Rev 23:299-323. doi:10.1128/CMR. 00068-09

223. Cohen TS, Prince A (2012) Cystic fibrosis: a mucosal immunodeficiency syndrome. Nat Med 18:509-519. doi:10.1038/nm. 2715

224. Adriaanse MPM, van der Sande LJTM, van den Neucker AM et al (2015) Evidence for a cystic fibrosis enteropathy. PLoS One 10: e0138062. doi:10.1371/journal.pone.0138062

225. Ramsey BW, Davies J, McElvaney NG et al (2011) A CFTR potentiator in patients with cystic fibrosis and the G551D mutation. N Engl J Med 365:1663-1672. doi:10.1056/ NEJMoa1105185

226. Painter RG, Valentine VG, Lanson NA et al (2006) CFTR expression in human neutrophils and the phagolysosomal chlorination defect in cystic fibrosis. Biochemistry 45:10260-10269. doi:10. 1021/bi060490t

227. Moriceau S, Lenoir G, Witko-Sarsat V (2010) In cystic fibrosis homozygotes and heterozygotes, neutrophil apoptosis is delayed and modulated by diamide or roscovitine: evidence for an innate neutrophil disturbance. J Innate Immun 2:260-266. doi:10.1159/ 000295791

228. Vandivier RW, Fadok VA, Hoffmann PR et al (2002) Elastasemediated phosphatidylserine receptor cleavage impairs apoptotic cell clearance in cystic fibrosis and bronchiectasis. J Clin Invest 109:661-670. doi:10.1172/JCI13572
229. Sedor J, Hogue L, Akers K et al (2007) Cathepsin-G interferes with clearance of Pseudomonas aeruginosa from mouse lungs. Pediatr Res 61:26-31. doi:10.1203/01.pdr.0000250043.90468.c2

230. Konstan MW, Byard PJ, Hoppel CL, Davis PB (1995) Effect of high-dose ibuprofen in patients with cystic fibrosis. N Engl J Med 332:848-854. doi:10.1056/NEJM199503303321303

231. Ren CL, Pasta DJ, Rasouliyan L et al (2008) Relationship between inhaled corticosteroid therapy and rate of lung function decline in children with cystic fibrosis. J Pediatr 153:746-751. doi:10.1016/ j.jpeds.2008.07.010

232. Pizzutto SJ, Upham JW, Yerkovich ST, Chang AB (2010) Inhaled non-steroid anti-inflammatories for children and adults with bronchiectasis. Cochrane Database Syst Rev CD007525. doi: 10.1002/ 14651858.CD007525.pub2

233. Konstan MW, Walenga RW, Hilliard KA, Hilliard JB (1993) Leukotriene B4 markedly elevated in the epithelial lining fluid of patients with cystic fibrosis. Am Rev Respir Dis 148:896901. doi:10.1164/ajrccm/148.4_Pt 1.896

234. Stelmach I, Korzeniewska A, Stelmach W et al (2005) Effects of montelukast treatment on clinical and inflammatory variables in patients with cystic fibrosis. Ann Allergy Asthma Immunol 95: 372-380. doi:10.1016/S1081-1206(10)61156-8

235. Tateda K, Ishii Y, Matsumoto T et al (2000) Potential of macrolide antibiotics to inhibit protein synthesis of Pseudomonas aeruginosa: suppression of virulence factors and stress response. J Infect Chemother 6:1-7. doi:10.1007/s101560000013

236. Schultz MJ (2004) Macrolide activities beyond their antimicrobial effects: macrolides in diffuse panbronchiolitis and cystic fibrosis. J Antimicrob Chemother 54:21-28. doi:10.1093/jac/dkh309

237. Southern KW, Barker PM, Solis-Moya A, Patel L (2012) Macrolide antibiotics for cystic fibrosis. Cochrane Database Syst Rev 11:CD002203. doi:10.1002/14651858.CD002203.pub4

238. Zarogoulidis P, Papanas N, Kioumis I et al (2012) Macrolides: from in vitro anti-inflammatory and immunomodulatory properties to clinical practice in respiratory diseases. Eur J Clin Pharmacol 68:479-503. doi:10.1007/s00228-011-1161-x

239. Binder AM, Adjemian J, Olivier KN, Prevots DR (2013) Epidemiology of nontuberculous mycobacterial infections and associated chronic macrolide use among persons with cystic fibrosis. Am J Respir Crit Care Med 188:807-812. doi:10.1164/ rccm.201307-1200OC

240. Jouneau S, Bonizec M, Belleguic C et al (2011) Anti-inflammatory effect of fluvastatin on IL-8 production induced by Pseudomonas aeruginosa and Aspergillus fumigatus antigens in cystic fibrosis. PLoS One 6:e22655. doi:10.1371/journal.pone.0022655

241. Ilmarinen P, Kankaanranta H (2014) Eosinophil apoptosis as a therapeutic target in allergic asthma. Basic Clin Pharmacol Toxicol 114:109-117. doi:10.1111/bcpt.12163

242. Joos S, Miksch A, Szecsenyi J et al (2008) Montelukast as add-on therapy to inhaled corticosteroids in the treatment of mild to moderate asthma: a systematic review. Thorax 63:453-462. doi:10. 1136/thx.2007.081596

243. Duffin R, Leitch AE, Sheldrake TA et al (2009) The CDK inhibitor, R-roscovitine, promotes eosinophil apoptosis by downregulation of Mcl-1. FEBS Lett 583:2540-2546. doi:10.1016/j. febslet.2009.07.017

244. Alessandri AL, Duffin R, Leitch AE et al (2011) Induction of eosinophil apoptosis by the cyclin-dependent kinase inhibitor AT7519 promotes the resolution of eosinophil-dominant allergic inflammation. PLoS One 6:e25683. doi:10.1371/journal.pone. 0025683

245. Farahi N, Uller L, Juss JK et al (2011) Effects of the cyclindependent kinase inhibitor R-roscovitine on eosinophil survival and clearance. Clin Exp Allergy 41:673-687. doi:10.1111/j. 1365-2222.2010.03680.x 
246. Reis AC, Alessandri AL, Athayde RM et al (2015) Induction of eosinophil apoptosis by hydrogen peroxide promotes the resolution of allergic inflammation. Cell Death Dis 6, e1632. doi:10. 1038/cddis.2014.580

247. Starosta V, Pazdrak K, Boldogh I et al (2008) Lipoxin A4 counterregulates GM-CSF signaling in eosinophilic granulocytes. J Immunol 181:8688-8699

248. Karra L, Haworth O, Priluck R et al (2015) Lipoxin $B_{4}$ promotes the resolution of allergic inflammation in the upper and lower airways of mice. Mucosal Immunol 8:852-862. doi:10.1038/mi. 2014.116

249. Polier G, Ding J, Konkimalla BV et al (2011) Wogonin and related natural flavones are inhibitors of CDK9 that induce apoptosis in cancer cells by transcriptional suppression of Mcl-1. Cell Death Dis 2, e182. doi:10.1038/cddis. 2011.66

250. Lucas CD, Allen KC, Dorward DA et al (2013) Flavones induce neutrophil apoptosis by down-regulation of Mcl-1 via a proteasomal-dependent pathway. Faseb J 27:1084-94. doi:10. 1096/fj.12-218990, Epub 2012 Nov 29

251. Lucas CD, Dorward DA, Sharma S et al (2015) Wogonin induces eosinophil apoptosis and attenuates allergic airway inflammation. Am J Respir Crit Care Med 191:626-636. doi:10.1164/rccm. 201408-1565OC 